\title{
Damage characterization and numerical simulation of shear experiment of plain woven glass-fiber reinforced composites based on 3D geometric reconstruction
}

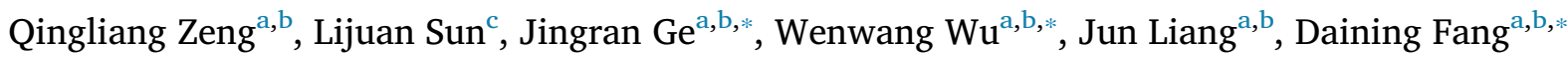 \\ ${ }^{a}$ Institute of Advanced Structure Technology, Beijing Institute of Technology, Beijing 100081, China \\ ${ }^{\mathrm{b}}$ Beijing Key Laboratory of Lightweight Multi-functional Composite Materials and Structures, Beijing 100081, China \\ ${ }^{\mathrm{c}}$ State Key Laboratory for Nonlinear Mechanics (LNM), Institute of Mechanics, Chinese Academy of Sciences, Beijing 100080, China
}

A R T I C L E I N F O

\section{Keywords:}

Computer tomography (CT)

In-situ experiment

Plain woven glass-fiber reinforced composites

Damage evolution characterization

\begin{abstract}
A B S T R A C T
The investigation on the effect of defects on the mechanical properties of composites is vital to explain the failure mechanism of materials. A computer tomography (CT) scanning in-situ shear test is designed to obtain u-CT images of plain weave glass-fiber reinforced composites. The images are then applied to reconstruct the samples by using image processing techniques. Damage evolution characterization of the plain weave glass-fiber composites under in-situ shear experiment are realized by visualizing damages in three dimension. The damage evolution process is compared with the numerical simulation results to verify the materials failure mode.
\end{abstract}

\section{Introduction}

Plain weave composite materials are widely applied in various fields due to the advantages of light weight and high strength. As for the main carrier, the existence of material cracks tends to reduce the performance and safety factor, and the expansion of internal cracks accelerate the failure of material. The process of weaving as well as the fiber volume fraction and geometric parameters of yarn are critical for accurately predict the strength of the material and the establishment of the analytical model [1,2]. Postle [3] and Sinoimeri [4] established a model by using energy method. Ge et al. [5] developed a new finite element numerical analysis model for predicting the fiber breakage and matrix fracture of braided composites. Considering the geometry of the fibers and matrix, Miravete et al. [6] proposed a new unit cell model based on the cell scheme. Lu et al. [7] studied the mechanical behavior of 3DF5D braided composites under tensile load by multi-scale simulation method, and analyzed the influence of weaving parameters on the tensile properties of braided composites. Simple geometric description is also an effective method to establish the woven materials model. Drach et al. [8] developed a new automated modeling tool, which solves the phenomenon of yarn interpenetration in traditional parametric modeling, and the establishment of models and numerical calculations are highly efficient. As the automated modeling software, WISETEX and TEXGEN are widely used in mesoscopic modeling of woven composites $[9,10]$. X-ray computer tomography provides a basis for geometric description of yarn. Sharma et al. [11] established a finite element analysis model by obtaining statistical geometric parameters of fibers from $\mu$-CT images. Blacklock and Bale [12-14] constructed a virtual sample as an analytical model. The Markov chain algorithm is used to calculate the yarn path, and the statistical geometric parameters are regard as calibration data to adjust the yarn. Naouar et al. [15] realized the process from scanning images to finite element models by using the structure tensor. In fact, it is difficult to obtain the geometric parameters of the yarn from scanning images. Huang et al. [16] developed a novel methodology, called 'Micro-CT Aided Geometric Modeling' (Micro-CT AGM), to construct geometric models of the material mesostructure from microtomographic images. For the first time, a new concept of 'material twin' was proposed, and a multiple factor morphological criterion was developed to assess the relative accuracy of the reconstructed geometric models. Djukic and Kosek et al. [17-19] proposed a variety of methods to enhance the visual contrast. The surface of the yarn is coated to distinguish the yarn profile, and the fiber made by other material in the yarn plays the role of marking the yarn path. Various of pre-processing methods are adopted to improve the images quality to obtain accurate geometric parameters as the calibration data for virtual samples. Void defects are always ignored in the previous modeling scheme, which makes the evaluation results of material mechanical performance are inaccurate. Ai et al. [20] obtained the material defect volume fraction based on the CT scanning experimental data. Monte Carlo function is used to select void defects to

\footnotetext{
* Corresponding author at: Institute of Advanced Structure Technology, Beijing Institute of Technology, Beijing 100081, China.

E-mail addresses: gejingran@bit.edu.cn (J. Ge), wuwenwang@bit.edu.cn (W. Wu), fangdn@bit.edu.cn (D. Fang).
} 
create the virtual samples of three-dimensional orthogonal woven $\mathrm{C} / \mathrm{C}$ composites. The comparison of the experimental and the numerical simulation results shows that the analysis results of void defects FEA model are more accurate.

As for a high efficient nondestructive testing technology, X-ray computer tomography is widely applied to observe the failure process of materials. Yousaf [21] performed a single-layer compaction experiment based on CT scanning, and the density and geometric parameters of the fiber bundle are used as criteria for evaluating the simulation results. Dietrich [22] proposed a new method for evaluating the damage of honeycomb core structure based on CT scanning technology. An in-situ tensile experiments of [0/90] S carbon fiber epoxy composites were carried out by Wright [23], and the propagation of damage inside the material was observed by synchrotron radiation scanning technique. As a kind of damage assessment method for composite materials, CT scanning loading experiment also applied to observe the damage of metal material. Williams [24] and Dezecot [25] prefabricated the 7075-T6 aluminum alloy samples, and compared the crack propagation of the aluminum alloy under different cycle times and cyclic loading conditions based on in-situ fatigue experiments. For material failure analysis, the damage evolution process is as critical as the failure mode. Martyniuk [26] observed the debonding of glass fiber, matrix and interface through in-situ experiment. Bohm [27] performed in-situ and ex-situ tensile tests on $[0 / 90]_{S}$ unidirectional fiber laminates and proved that CT in-situ experiments have higher resolution and shorter scan times. The in-situ experiment is divided into two modes: fast scanning and interrupted load scanning. When the material has rapid deformation, a fast scan can capture a clearer image [28]. Mazars et al. [29] performed an in-situ tensile tests on $\mathrm{SiC} / \mathrm{SiC}$ materials at room temperature and at $1250 \mathrm{C}$, respectively, and the location of the initial crack was verified by the finite element method. Perrier et al. [30] analyzed the effect of water aging on the damage evolution of woven hemp/epoxy composites under tensile loading.

In this study, X-ray computed tomography is applied to capture the geometric features inside the material and to record the damage process at various stages of the in-situ shear experiment. The grayscale images collected by CT scan experiments are applied to analyze the manufacturing defects and extract geometric parameters to create a variety of finite element models. The data obtained by in-situ experiments provide a basis for the analysis of material damage evolution, and the generation, distribution and evolution of cracks are shown in detail. Various of finite element models are proposed for numerical simulation and compared with the experimental results to analyze the effect of void defects on the mechanical properties and verify the initial damage form of the material.

\section{Materials and in-situ experiment}

\subsection{Materials}

The plain woven glass-fiber provided by Nanjing Fiberglass Research and Design Institute is utilized as the reinforced material of sample, and the materials specification of the laminate are shown in Table 1. In order to achieve the shearing effect, the size of sample is certain designed and processed. There are two main considerations in the design of the sample: the yarn section has enough cells and ensures that the image of section is clear enough. The shear sample is designed as Fig. 1(a), and it size is shown in Fig. 1(b). The thickness of laminate

Table 1

Materials specification of the laminate.

\begin{tabular}{llll}
\hline $\begin{array}{l}\text { Yarn count } \\
(\mathrm{Tex})\end{array}$ & $\begin{array}{l}\text { Areal density } \\
(\mathrm{g} / \mathrm{m} 2)\end{array}$ & $\begin{array}{l}\text { Total fibre volume } \\
\text { fraction }(\%)\end{array}$ & $\begin{array}{l}\text { Fibre volume fraction } \\
\text { in warp (\%) }\end{array}$ \\
\hline 2.60 & 0.34 & 44 & 37 \\
\hline
\end{tabular}

is $3 \mathrm{~mm}$. The wide of sample is big enough that the scan area can capture at least three cells, allowing the scan resolution to reach the um level.

\subsection{In-situ shear experiment}

The micro-structure in mesoscale of composite can be reconstructed by $\mu$-CT, and the microfocus ray source device is XWT-240-CT imported from Vaux, Germany. This equipment has a $225 \mathrm{KV}$ and $2000 \mu \mathrm{A}$ nanofocus X-ray tube and the minimum voxel sizes up to $4 \mathrm{um}$, and the $\mu$ CT equipment is shown in Fig. 2. The source voltage and current in this in-situ test are $160 \mathrm{KV}$ and $150 \mu \mathrm{A}$, respectively. The voxel size is 23.5 um, and the magnification is up to 45 times, and the scanning area size is $40 \mathrm{~mm} \times 16 \mathrm{~mm} \times 3 \mathrm{~mm}$. The in-situ shear experiment comprises the following steps:

(1) CT scan experiment is performed prior to in-situ experiments to capture geometric features inside the material. Frist of all, the sample is fixed on the turntable. The rotation speed of turntable is set to $0.18^{\circ} / \mathrm{s}$, and the scan range is from $0^{\circ}$ to $360^{\circ}$. The scan time is $2000 \mathrm{~s}$, and exposure time for each projection is $1 \mathrm{~s}$ to get $2000 \mu$ CT images.

(2) After the scan is completed, the test machine is started to stretch the sample. When the displacement reaches $2 \mathrm{~mm}$, the stretching operation is stopped. A CT scan experiment is performed immediately, and the load is constant during the scan. The rotation speed of the turntable is set to $0.6^{\circ} \mathrm{s}$, and Scanning range is from $0^{\circ}$ to $360^{\circ}$. The time of scan is $600 \mathrm{~s}$, and exposure time for each projection is set to $1 \mathrm{~s}$ to get $600 \mu$-CT images. The above steps are repeated when the displacement is reaches $4 \mathrm{~mm}, 5 \mathrm{~mm}, 6 \mathrm{~mm}, 7 \mathrm{~mm}, 7.6 \mathrm{~mm}$.

Seven sets of $\mu$-CT images are collected and reconstructed by VG STUDIO to get the three views of sample. The step 1 reconstruction image is shown in Fig. 3, and the yarn is shown in Fig. 3(a). At the initial loading stage, material didn't generate damages. When the displacement reaches $4 \mathrm{~mm}$, the shear area begins to generate cracks. As the displacement increases, the sample eventually failed due to the rapid expansion of the crack, and the whole process is shown in Fig. 4. The specific parameters of scanning are shown in Table 2 .

The displacement is converted to shear strain to describe the shearing of the material in an accurate way. The shear area is the red square part as shown in Fig. 5, which is deformed into a parallelogram as shown in Fig. 6 under the effect of shear load along the x-axis. The deformation of shear area is small enough that suppose the $\alpha \approx \tan \alpha$. The shear strain can be determined from Eq. (1):

$$
\left\{\begin{array}{l}
\varepsilon_{x y}=\frac{1}{2} \gamma_{x y} \\
\gamma_{x y}=\alpha_{x y}+\alpha_{y x} \\
\alpha_{x y} \approx \tan \alpha_{x y}=\frac{a u}{n b l}
\end{array}\right.
$$

where $\varepsilon_{x y}$ is the shear strain of $\mathrm{x}-\mathrm{y}$ plane, and $\alpha_{x y}$ is the rotation angle of edge $\mathrm{AB}$. The $a, b$ are the length and width of the shear area. $l$ is the length of sample, and $n$ is the number of unit cell in the shear area. $u$ is the displacement.

\section{Damage evolution process characterization and data processing}

The 3D model based on gray image of plain woven composites can be generated by 3D reconstruction. The composition of yarn and matrix are quite different, which results in different levels of X-ray absorption, and the yarn and matrix exhibit different grayscale intervals due to differences in the grayscale values of the different material compositions displayed in the image. An image segmentation algorithm is used to separate yarn and substrates. For the weft yarn and warp yarn, it is difficult to separate them only using the image segmentation algorithm. 


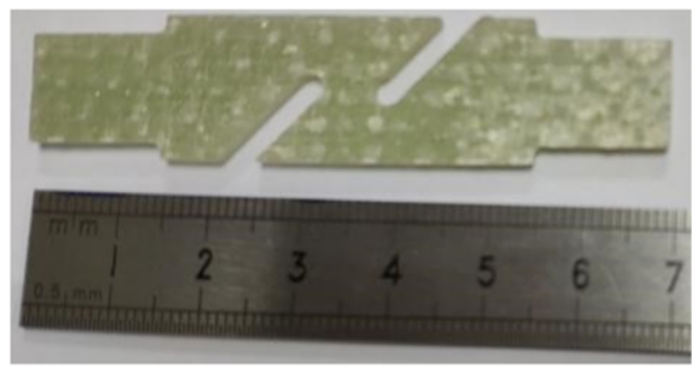

(a)

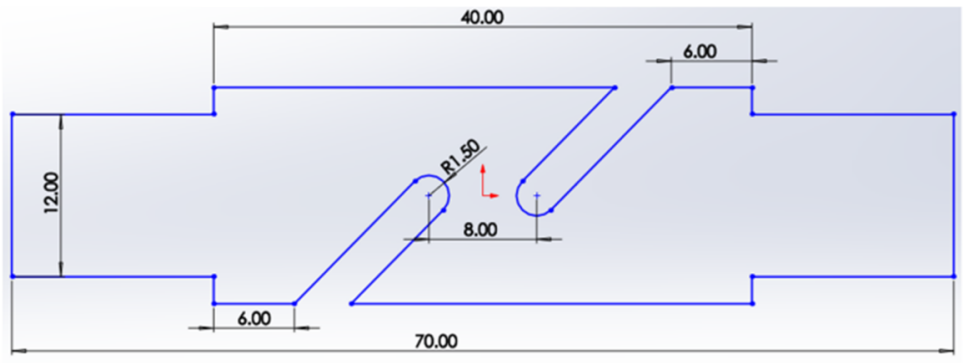

(b)

Fig. 1. Plain woven glass-fiber reinforced shear specimen: (a) Shear specimen; (b) The size of specimen.

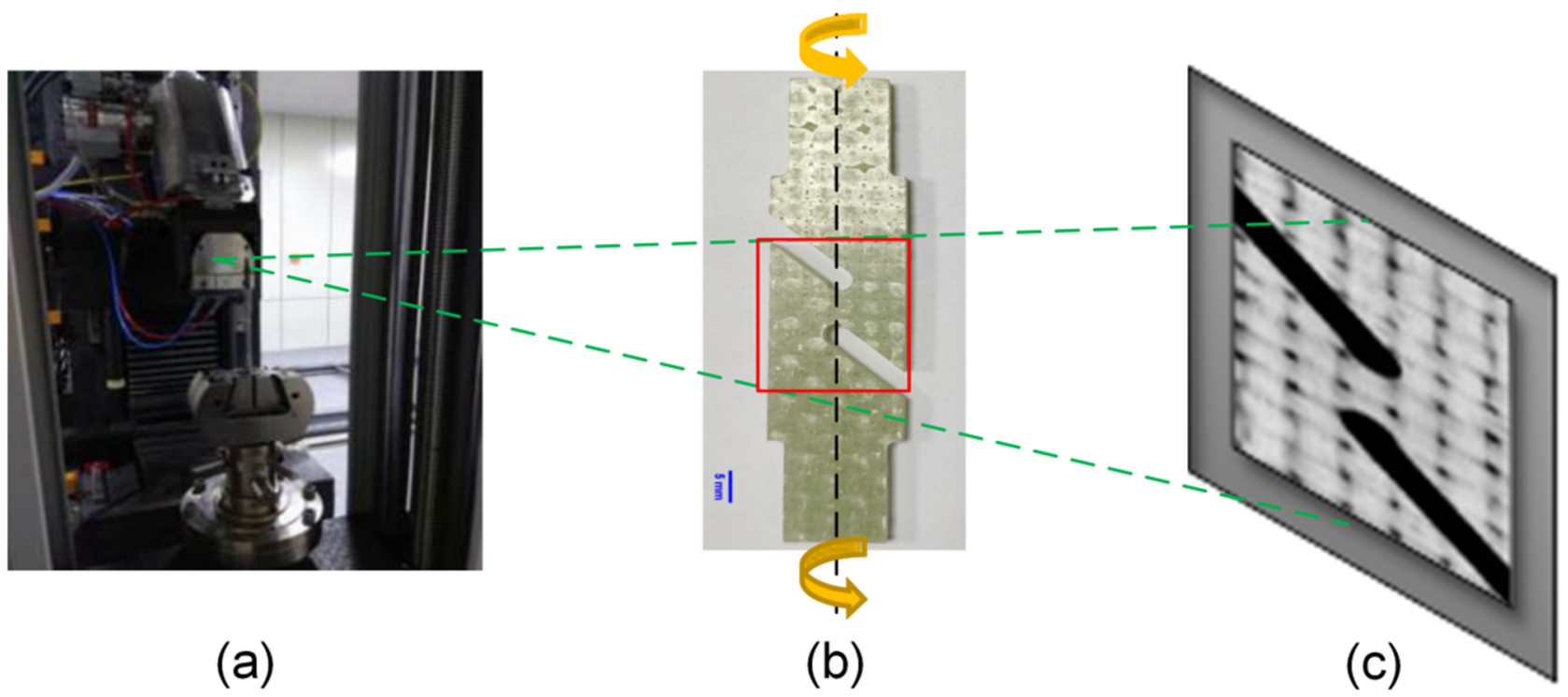

Fig. 2. The computer tomography equipment: (a) X-ray source; (b) Sample; (c) Planar detector.
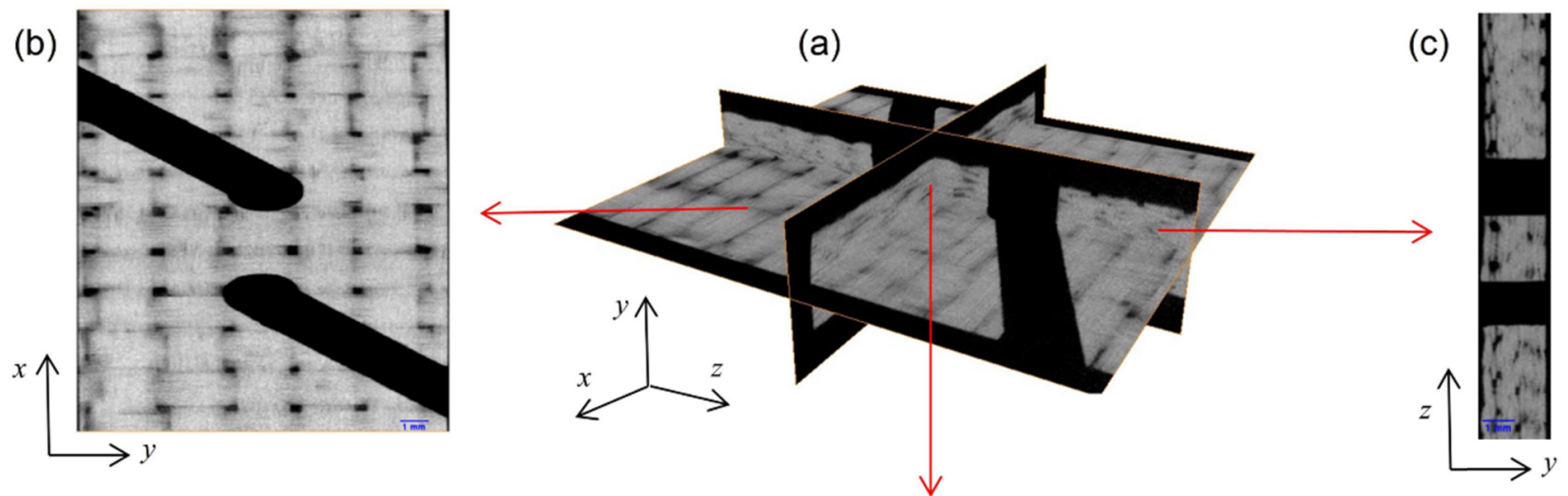

(d)

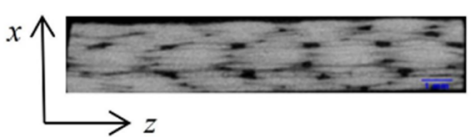

Fig. 3. Step 1 reconstruction image: (a) Axonometric; (b) X-Z plane; (c) Y-Z plane; (d) X-Y plane. 


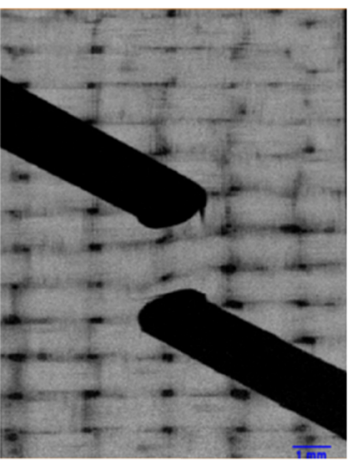

(a)

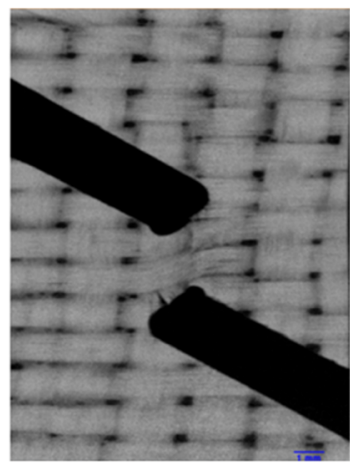

(b)

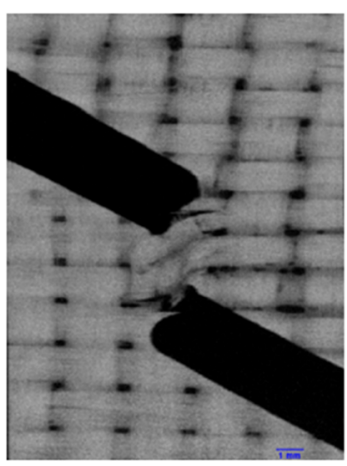

(c)

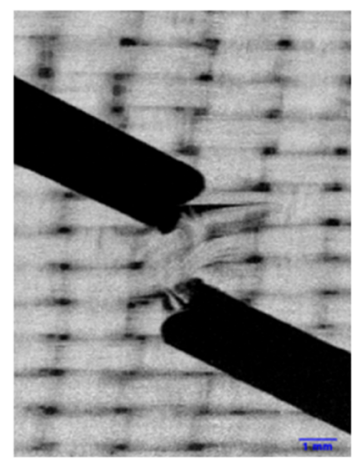

(d)

Fig. 4. Reconstruction image: (a) Step 4; (b) Step 5; (c) Step 6; (d) Step 7.

Table 2

Scanning parameters.

\begin{tabular}{lllll}
\hline Step & $\begin{array}{l}\text { Scan time } \\
(\mathrm{s})\end{array}$ & Displacement $(\mathrm{mm})$ & $\begin{array}{l}\text { Shear strain } \\
(\mathrm{rad})\end{array}$ & $\begin{array}{l}\text { Turntable speed } \\
(\% / \mathrm{s})\end{array}$ \\
\hline 1 & 2000 & 0 & 0 & 0.18 \\
2 & 600 & 2 & 0.0089 & 0.6 \\
3 & 600 & 4 & 0.0119 & 0.6 \\
4 & 600 & 5 & 0.0149 & 0.6 \\
5 & 600 & 6 & 0.0179 & 0.6 \\
6 & 600 & 7 & 0.0208 & 0.6 \\
7 & 600 & 7.6 & 0.0227 & 0.6 \\
\hline
\end{tabular}

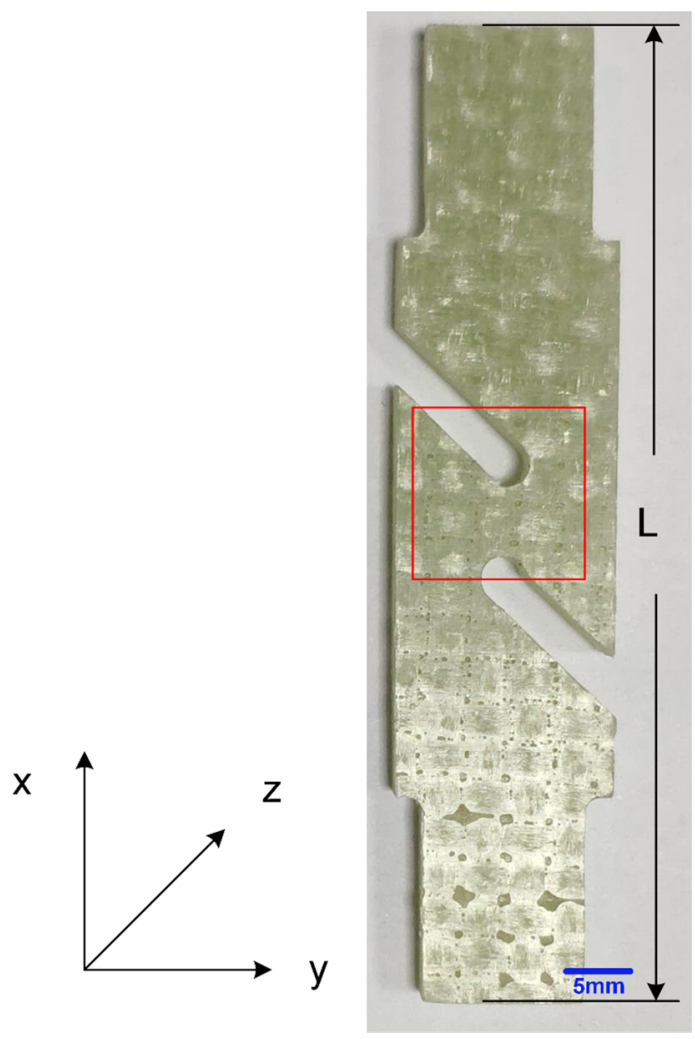

Fig. 5. Shear area of sample.

These two yarns are prepared from the same material, and have the same interval in the gray value of the image. The pixel width and resolution are the main factors that determine image quality, and the

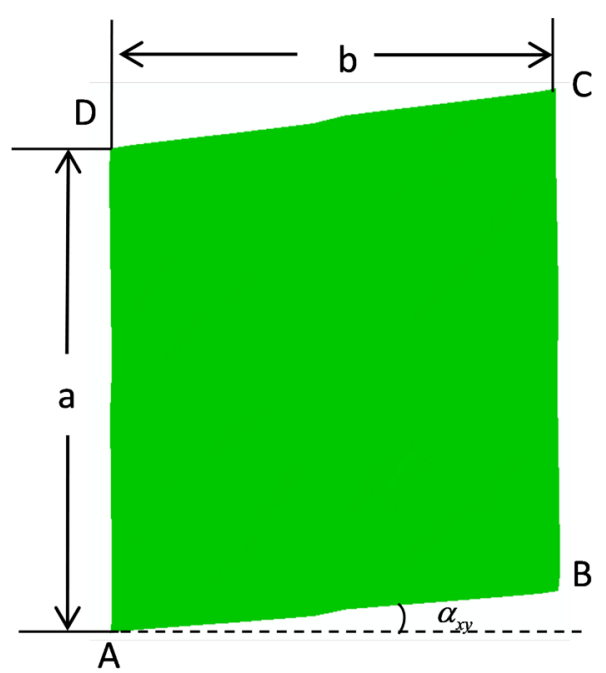

Fig. 6. The expression of shear strain at the shear area.

yarn's contour can be clearly captured with a high resolution. If the yarn profile reaches a certain pixel width, the contour of different yarn can be marked by threshold division to obtain a successfully separated yarn.

In fact, the contact between the warp yarn and the weft yarn becomes very close during the preparation process due to the mature laminating process. The contour of the yarn cannot be distinguished, when the gap between yarns is smaller than the resolution of the CT scanning device. In order to characterize a yarn, the image of the yarn is obtained in one cycle. At the crests and troughs of the path, the gap between the yarns becomes very small and it is difficult to obtain a complete contour of the yarn in one cycle. There are two ways to obtain yarn information, one is to obtain the yarn geometry by marking the section [31], and the other is to identify and simplify the yarn by the morphological algorithm. Blacklock [12] adopted the Markov chain algorithm to calculate the yarn path, and Naouar [15] separate the yarn to obtain a yarn geometric model by using the skeleton algorithm structure tensor. The yarn boundaries can be easily distinguished by using fabric coating or resin additives during the material preparation, and the fiber made by other material in the yarn play the role of making the yarn path. In this paper, the geometric parameters are obtained by marking the yarn cross-section.

\subsection{Measurement of yarn cross section parameter}

The yarn cross section $\mu$-CT image is from the top view of the sample as indicated by the red square in Fig. 7(a). The yarn cross section has a 


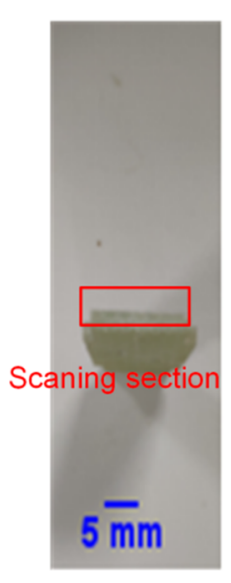

(a)

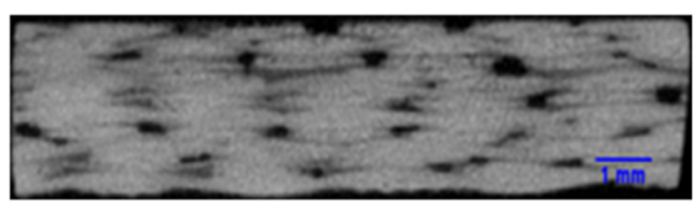

(b)

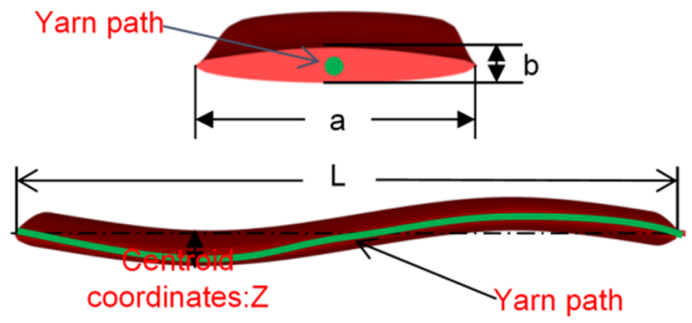

(d)

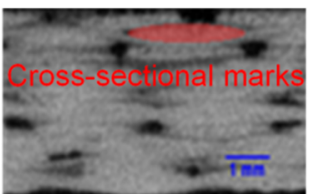

(c)

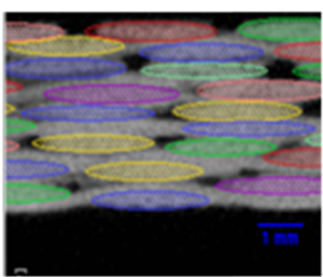

(e)

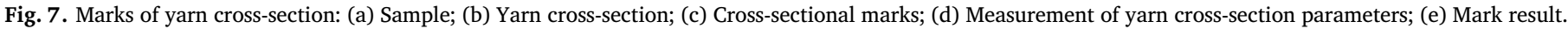

Table 3

Yarn global average characteristic parameter.

\begin{tabular}{llc}
\hline $\mathrm{a}(\mathrm{mm})$ & $\mathrm{b}(\mathrm{mm})$ & $\mathrm{L}(\mathrm{mm})$ \\
\hline 2.50 & 0.36 & 5.78 \\
\hline
\end{tabular}

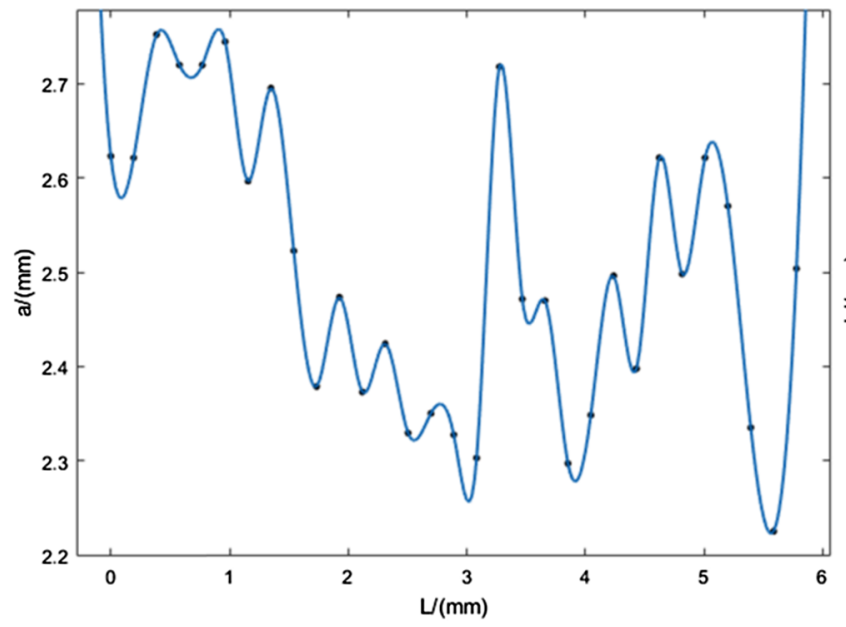

(a) variety of shapes similar to ellipse as Fig. 7(b), and it is feasible to simplify the yarn cross section with an ellipse [32,33]. Different colors are used to mark the adjacent yarns section as shown in Fig. 7(e), and the marks are measured by using AVIZO 9 to obtain the yarn crosssectional characteristics. In order to reduce the deviation of the statistical data and delete the amount of statistical data, a limited number of

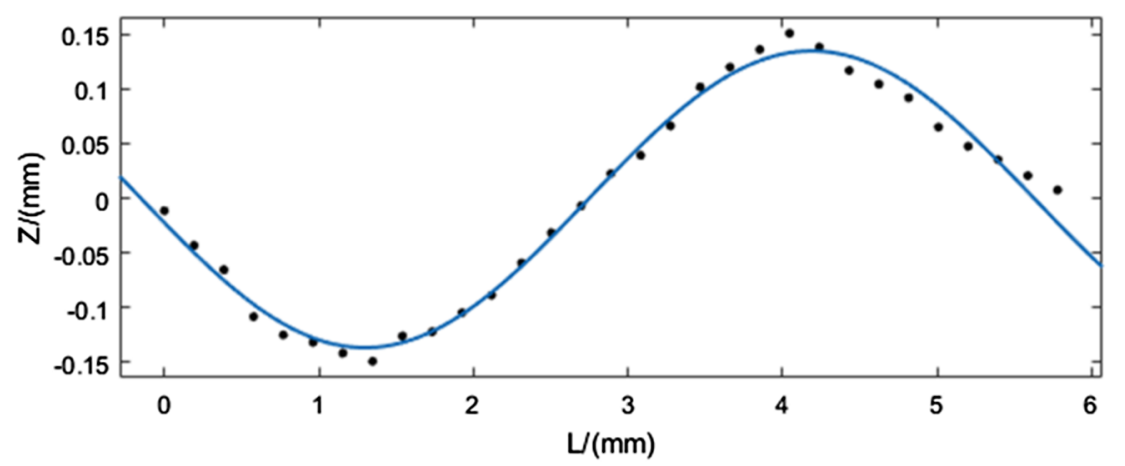

(c)

Fig. 8. Yarn parameter statistics: (a) Systematic curve of major axis; (b) Systematic curve of minor axis; (c) Systematic curve of yarn path coordinates. 


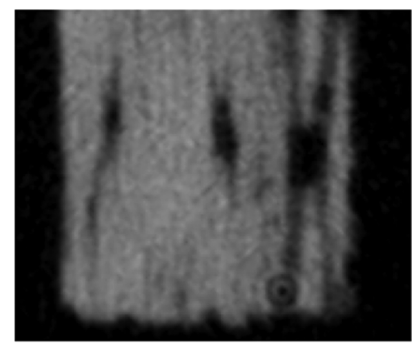

(a)

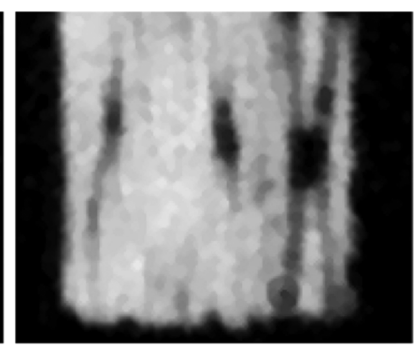

(b)
Fig. 9. Median filter processing: (a) Original image; (b) Filtered image.

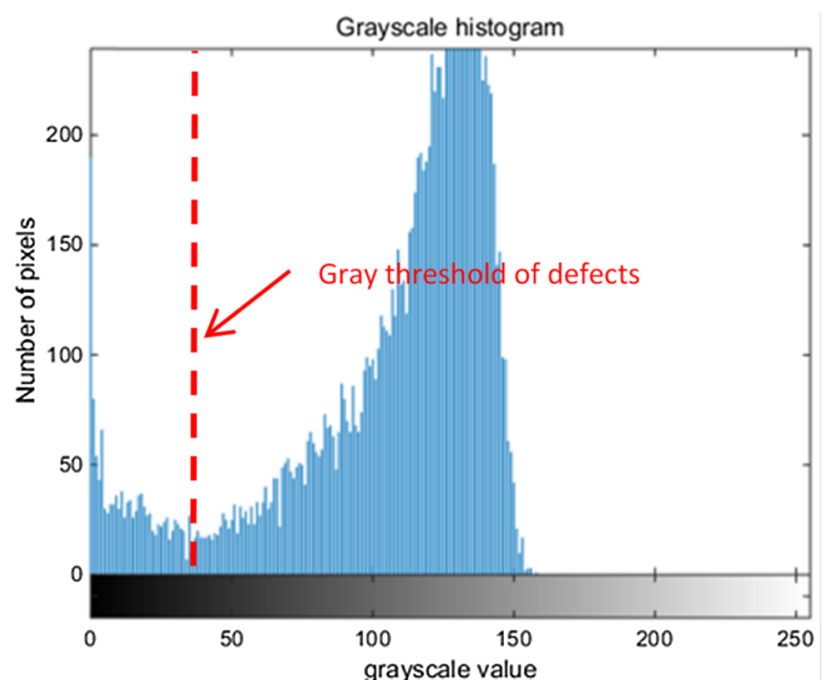

Fig. 10. Gray histogram of $\mu-C T$ images. slices of equal spacing are selected for marking. A section of the number of cycles (from NO. 400 to NO. 550 pieces) is selected for statistical analysis every 5 slices, and the interval of slice is $0.0388 \mathrm{~mm}$. The major axis and minor axis of the ellipse are respectively denoted as a and b. The yarn cycle length is denoted as $\mathrm{L}$, and the centroid coordinates is denoted as Z [34-36]. The yarn average characteristic parameters are shown in Table 3.

The distribution of $\mathrm{a}$ and $\mathrm{b}$ along the length of the cycle length is shown in Fig. 8(a) and (b). The major and minor axes of the yarn section show irregular fluctuations, so the statistical average is used as the basis for subsequent modeling. The yarn path statistics of Fig. 8(c) are close to a trigonometric function, which is prove that the measured parameters are accuracy.

\subsection{Measurement of void defects}

During the scanning process, external disturbances and the rotation of equipment will make the $\mu$-CT images generate noise. In this paper, a MATLAB procedure is applied to process $\mu$-CT images of cross-section slices. The median filter function is used to smooth images and reduce the noise of ring artifacts, and the noise reduction effect is shown in the Fig. 9.

The first important step of characterize the process of damage evolution is to distinguish the yarn from the matrix. Matrix voxels can be easily distinguished from yarn voxels due to the matrix voxels low grey scale intensity. A grayscale histogram of the $\mu$-CT images is retrieved by the imhist function of MATLAB (Fig. 10), and the grayscale image exists two peaks due to the higher grayscale value of the material and the lower grayscale value of the void defects. In this study, the maximum entropy is adopted to get the segmentation threshold point of void defects [37]. The grayscale threshold is set to 40 , and the function of threshold segmentation of the image processing software AVIZO 9 is used to separate the defect [38]. The three views of segmentation image are shown in Fig. 11(a), and the void defects is marked in blue. The distribution of small defects existing on the sample are shown in Fig. 11(b), which is consistent with the result of threshold segmentation. The three-dimensional reconstruction of the void defects is shown in Fig. 12(a), and the shape of the void defects is spherical or

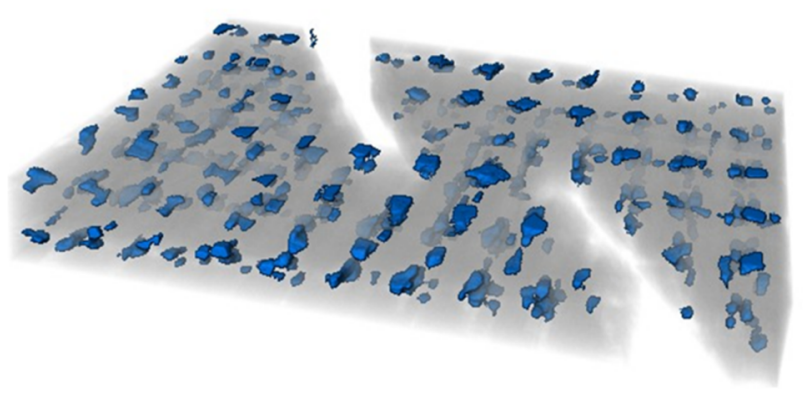

(a)
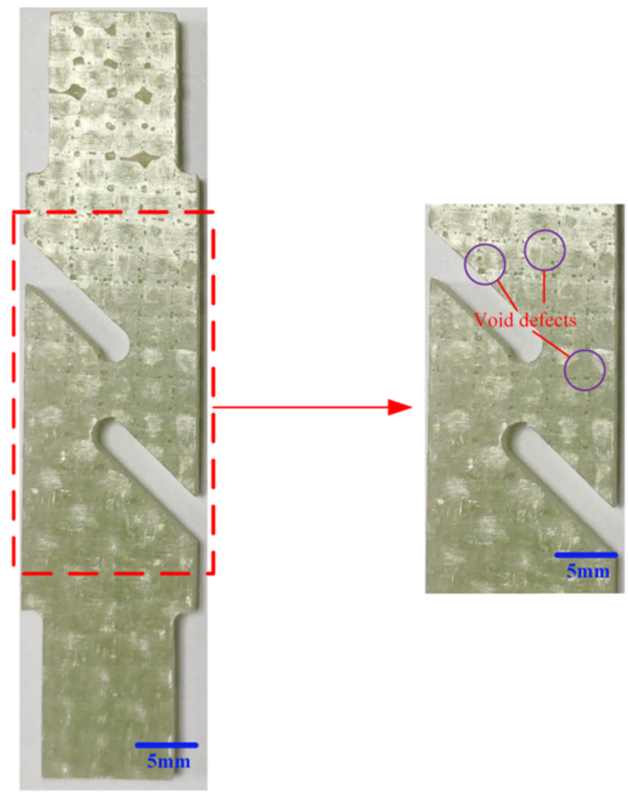

(b)

Fig. 11. Mark of void defects: (a) Three views of segmentation image; (b) The distribution of defects existing on the sample. 


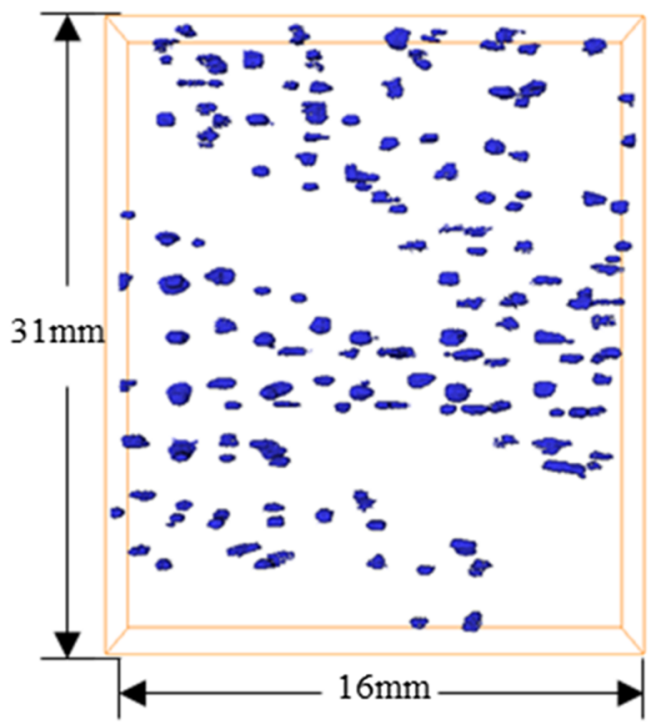

(a)

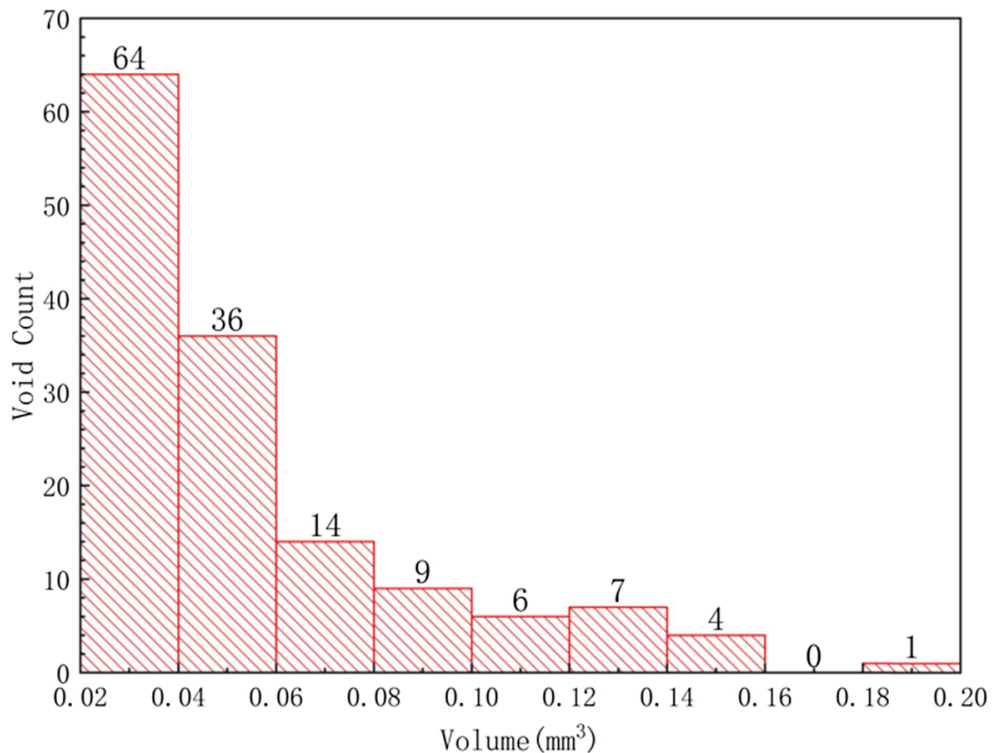

(b)

Fig. 12. Void defect statistical analysis: (a) Three-dimensional reconstruction of void defects; (b) Volume statistical histogram of void defects.

ellipsoidal. Most of the void defects are concentrated on the matrix at the junction of the warp and weft yarns, and the volume statistics of the void defects are shown in Fig. 12(b). The volume fraction of voids can be determined from Eq. (2):

$V_{\%}=\frac{V_{\text {void }}}{V} \times 100 \backslash \%$

where $V_{\text {viod }}$ represents the defect volume, and $V$ represents the volume of the statistical region. $V_{\%}$ represents the defect volume fraction.

The number of statistical void defects is 141 , and the average volume of defects is $0.0566 \mathrm{~mm}^{3}$. The total volume of void defects is $7.9806 \mathrm{~mm}^{3}$, and the size of the box region for extracting defects is $16 \mathrm{~mm} \times 31 \mathrm{~mm} \times 3 \mathrm{~mm}$. Therefore, the void defects volume fraction of material is $0.54 \%$.

\subsection{Damage evolution characterization}

The geometric model of sample is reconstructed in three dimensions using the image processing software AVIZO 9, and the reconstruction model is shown in Fig. 13(a). The warp and weft yarns are distinctive, which is the basis for crack classification. The cracks are concentrated

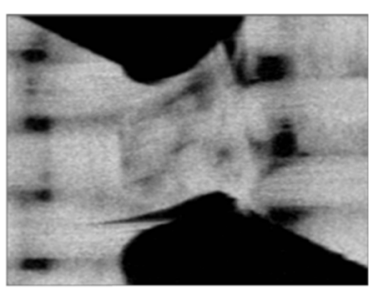

(a)

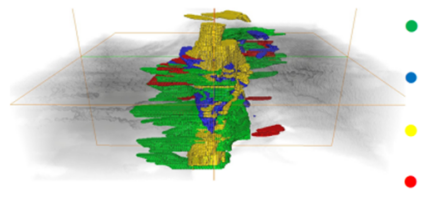

(c)

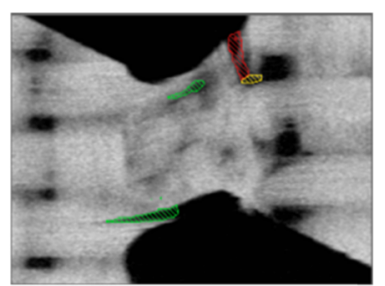

(b)
Fig. 14. Crack marking and 3D visualization: (a) Shear area; (b) Cracks marking; (c) Cracks distribution.

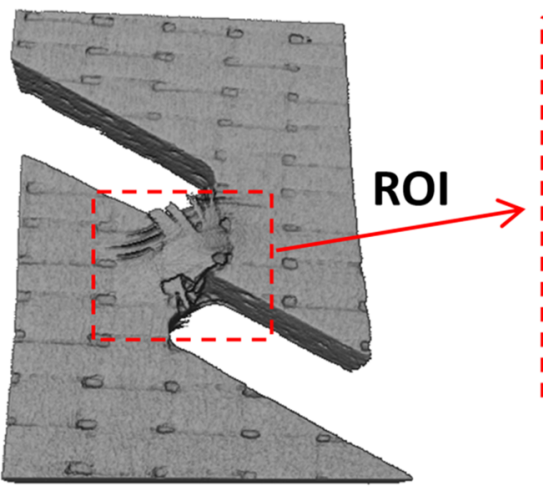

(a)

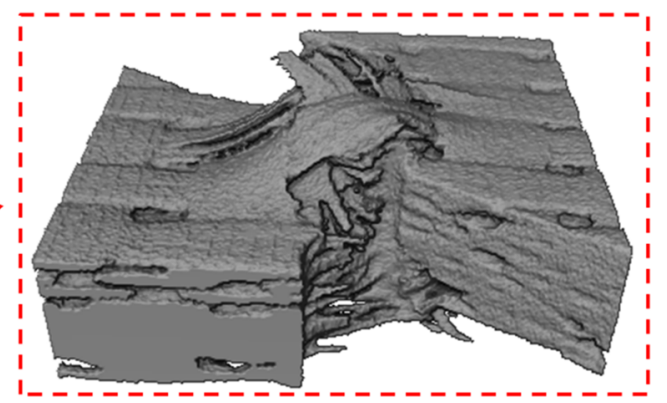

(b)

Fig. 13. Reconstruction model: (a) Reconstruction model of shear sample; (b) Reconstruction model of shear area. 


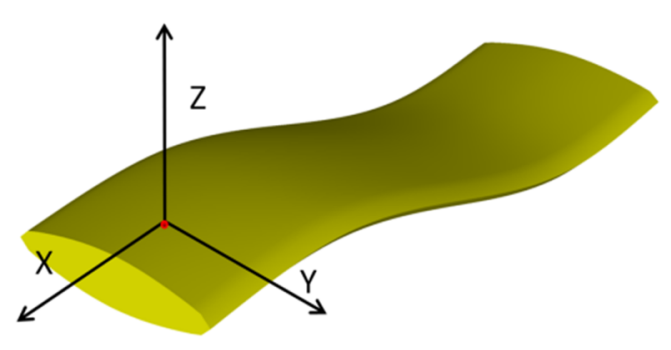

(a)

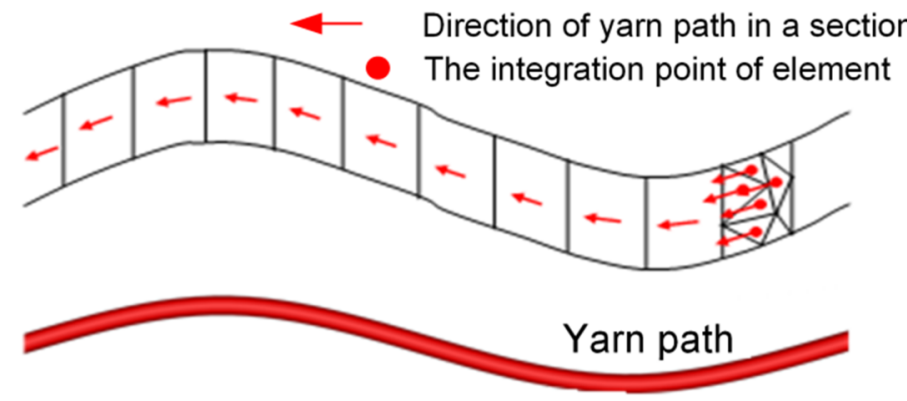

(b)

Fig. 15. The coordinate of yarn: (a) Definition of local coordinates; (b) Definition of material direction.

Table 4

Material properties of matrix and yarn.

\begin{tabular}{|c|c|c|c|c|c|c|}
\hline Matrix & $\begin{array}{l}E_{m}(\mathrm{GPa}) \\
9.36\end{array}$ & $\nu_{m} 0.33$ & $\begin{array}{l}X_{\mathrm{m}, t}(\mathrm{MPa}) \\
82\end{array}$ & $\begin{array}{l}X_{m, c}(\mathrm{MPa}) \\
100\end{array}$ & $\begin{array}{l}S_{m, s}(\mathrm{MPa}) \\
50\end{array}$ & $\begin{array}{l}G_{m}(\mathrm{~N} / \mathrm{mm}) \\
1.00\end{array}$ \\
\hline \multirow[t]{4}{*}{ Yarn } & $E_{f, 1}(\mathrm{GPa})$ & $E_{f, 2(3)}(\mathrm{Gpa})$ & $\nu_{f, 12(13)}$ & $\nu_{f, 23}$ & $G_{f, 12(13)}(\mathrm{GPa})$ & $G_{f, 23}(\mathrm{GPa})$ \\
\hline & 23.508 & 9.404 & 0.137 & 0.312 & 4.348 & 2.894 \\
\hline & $X_{f, 1 t}(\mathrm{MPa})$ & $X_{f, 1 c}(\mathrm{MPa})$ & $Y_{f, 2 t}(\mathrm{MPa})$ & $Y_{f, 2 c}(\mathrm{Mpa})$ & $S_{f}(\mathrm{MPa})$ & $G_{f}(\mathrm{~N} / \mathrm{mm})$ \\
\hline & 490.52 & 143.93 & 24.7 & 8.2 & 68.53 & 6.0 \\
\hline
\end{tabular}

in the sheared area of the center part, and the area of $10 \mathrm{~mm} \times 12 \mathrm{~mm} \times 3 \mathrm{~mm}$ is cut out of the $\mu$-CT image as a region of interest (ROI). The reconstruction model is shown in Fig. 13(b). The following steps for processing the $\mu$-CT image data is repeated at each stage of the shear experiment: Firstly, the cracks are divided into transverse crack and longitudinal crack according to the orientation of cracks using top hat segmentation. Then, the cracks are divided into warp crack, weft crack according to the location of cracks.

Four different types of cracks are distinguished as shown in Fig. 14(b): warp transverse cracks, warp longitudinal cracks, weft transverse cracks and weft longitudinal cracks. The cracks on the slice are marked with different colors as Fig. 14(c), and 200 equidistant slice samples is select to repeat the step. All of the slices are marked using the interpolation function to obtain the overall distribution of the cracks $[39,40]$.

\section{Finite element analysis}

\subsection{Progressive damage model}

The failure criteria adopted in this paper are based on the continuous formula of strain failure, and different failure criteria are applied to the matrix and the yarn [20]. A local coordinates system of the yarn is built as Fig. 15(a), the direction " $x$ " represents the longitudinal direction of the yarn, and the direction " $y$ " represents the transverse direction of the yarn. A yarn is divided into a finite number of regions,

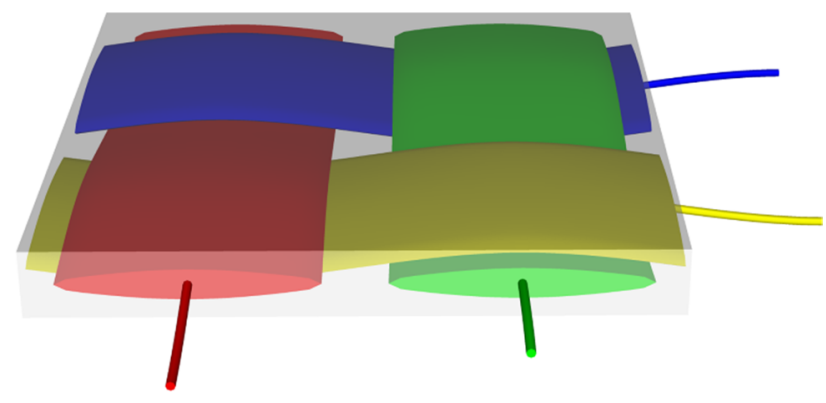

Fig. 16. Yarn path and unit cell model. and the local direction is defined according to the tangent of the yarn path as Fig. 15(b). The elements of same region are given the same main direction, and the material direction of the entire unit cell is imparted in this way. The failure mode of the material is judged by the failure criteria and the damage evolution law. In this study, only the longitudinal failure direction and transverse direction failure are considered as the failure modes of yarn. The yarn is considered to be a transversely isotropic material and the matrix is regarded as an isotropic material [41-43]. A detailed description of the progressive damage theory model is described in Appendix A.

\subsection{Material parameters}

The shear sample is prepared from plain weave glass-fiber reinforced composites, and the yarn is considered to be a transversely isotropic material and the matrix is regarded as an isotropic material. The material properties of glass fiber taken from Refs. [20,44], and the Chamis empirical formulae [45] are applied to calculate the stiffness and strength of the yarn. The material properties of the yarn and matrix are listed in Table 4.

\subsection{Unit cell model}

The average yarn characteristic parameters and yarn path coordinates have been obtained from the image processing in the previous Section 3.1, and the parameter of the warp yarn and the weft yarn are measured separately. A unit cell model is created using the weaving modeling software TEXGEN [46] as Fig. 16. There are only a small number of areas in the modeling process that have intersection problems between yarns, which can be avoided by slightly adjusting the centroid coordinates of the area.

The major axis of yarn section is $2.50 \mathrm{~mm}$, and minor axis is $0.36 \mathrm{~mm}$. The yarn cycle length is $5.78 \mathrm{~mm}$, and the size of unit cell is $5.78 \mathrm{~mm} \times 5.78 \mathrm{~mm} \times 0.80 \mathrm{~mm}$. Periodic boundary conditions are applied to the unit cell to simulate the effect of the multilayer fabric, and the detailed theoretical analysis is described in Appendix B.

\subsection{Verification of mesh convergence}

The size of the mesh determines the accuracy of the finite element 


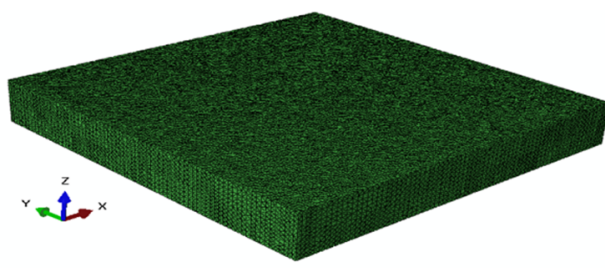

(a)

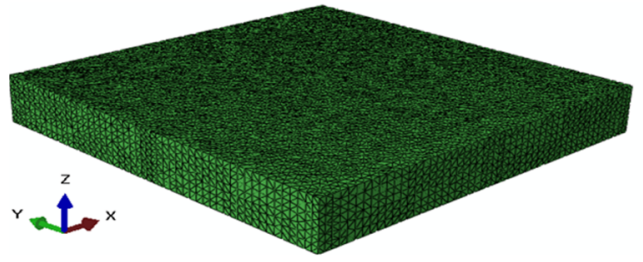

(c)

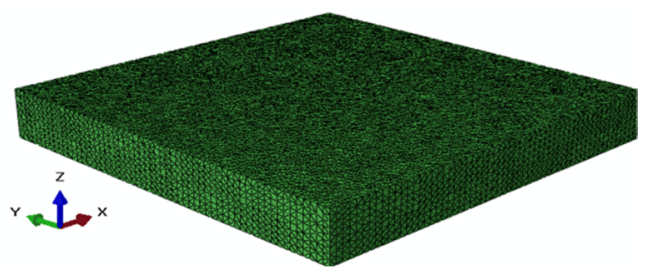

(b)

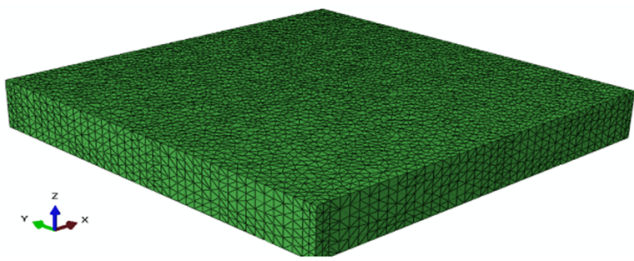

(d)

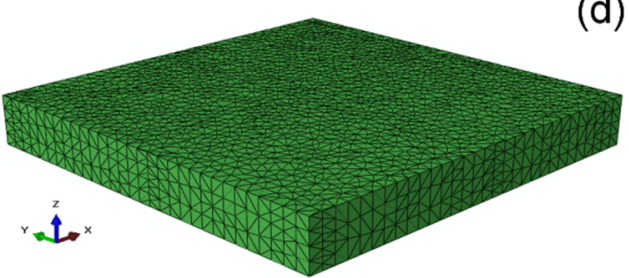

(e)

Fig. 17. Unit cell models of various sizes (f): (a) $f=0.08 \mathrm{~mm}$; (b) $f=0.10 \mathrm{~mm}$; (c) $f=0.12 \mathrm{~mm}$; (d) $f=0.15 \mathrm{~mm}$; (e) $f=0.20 \mathrm{~mm}$.

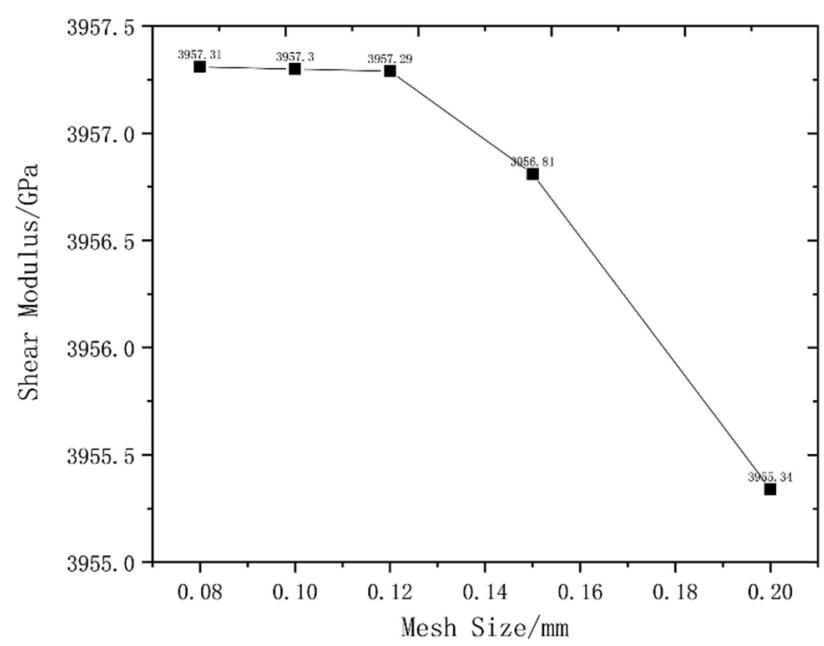

Fig. 18. Effects of mesh size on modulus.

calculation results. When the mesh size is small to a certain extent, the mesh tends to converge and the calculation result tend to be constant. The convergence of the mesh can ensure the accuracy of the calculation result while reducing the amount of calculation. The unit cell model with different grid sizes is established as shown in Fig. 17, and shear simulation are performed on these models. The influence of mesh size on shear modulus is shown in Fig. 18. When the mesh size $f$ of model is less than or equal to $0.12 \mathrm{~mm}$, the calculated shear modulus tends to be constant. Therefore, $0.12 \mathrm{~mm}$ is the convergence size of the model mesh.

\subsection{Finite element model}

\subsubsection{General finite element model}

The geometric model is meshed using TEXGEN software, and the FEA model with $0.12 \mathrm{~mm}$ size mesh is generated. The FEA model consists of two components: the yarn and the matrix (Fig. 19). The element mesh type is C3D4, and the number of mesh is 180,800. The contact between yarn and matrix, matrix and matrix is set as the grid common node. The general periodic boundary condition is set as boundary condition, and a UMAT subroutine is applied to progressive damage analysis.

\subsubsection{Void defects finite element model}

In the Section 3.2, the volume fraction of void defects is calculated to be $0.54 \%$. An inp file of FEA model is imported into ABAQUS, and a script which is based on the Monte Carlo function is adopted to select the element as void defects [47]. The specific procedure steps as

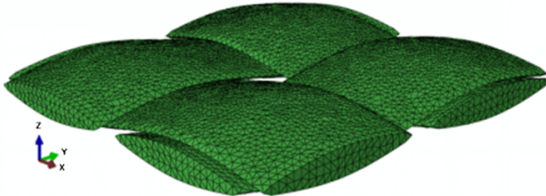

(a)

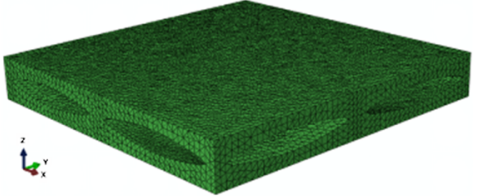

(b)

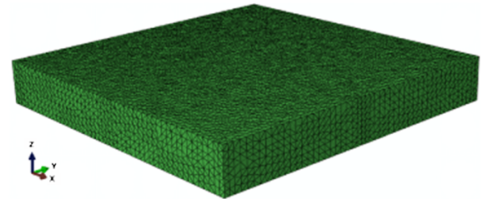

(c)

Fig. 19. FEA model and its components: (a) Glass fiber yarn; (b) Epoxy matrix; (c) Whole composite. 


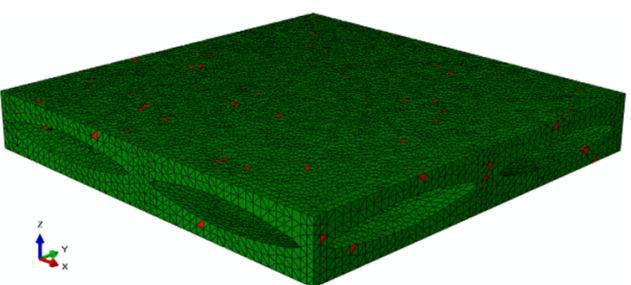

(a)

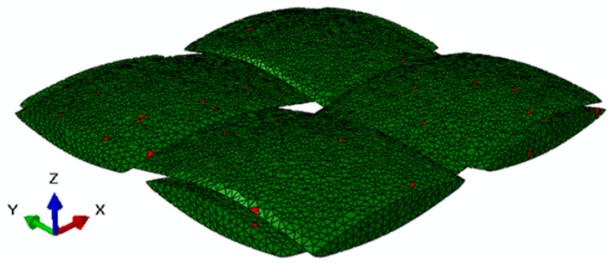

(b)

Fig. 20. FEA model with different defect content: (a) Matrix model with $0.54 \%$ volume defects; (b) Yarn model with $0.54 \%$ volume defects.

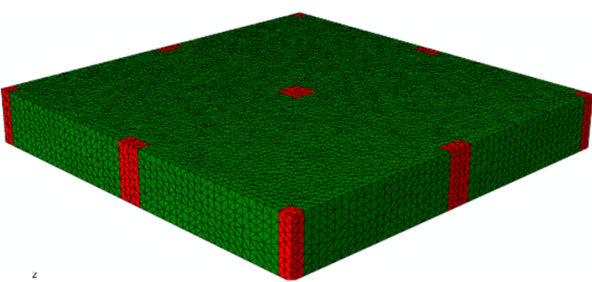

(a)

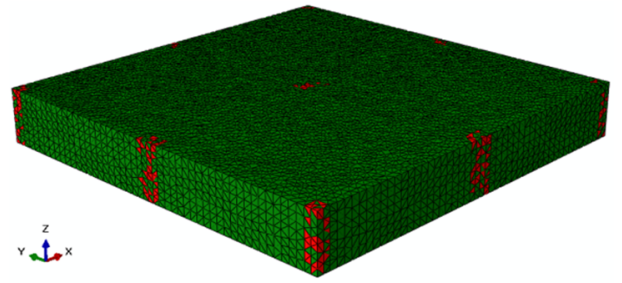

(c)

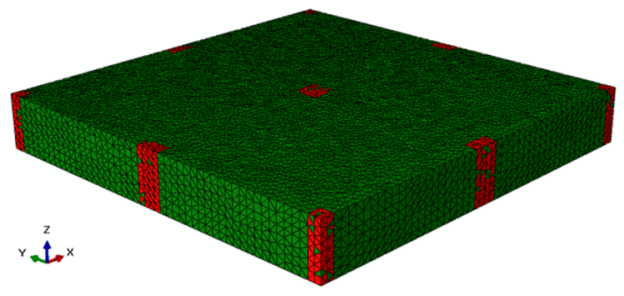

(e)

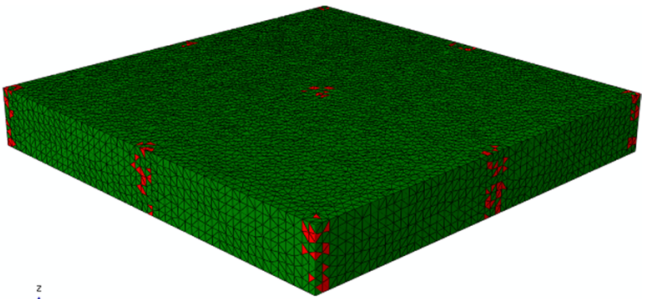

(b)

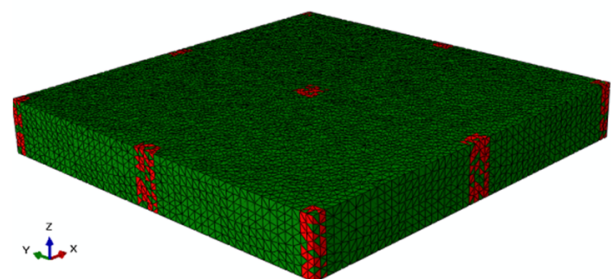

(d)

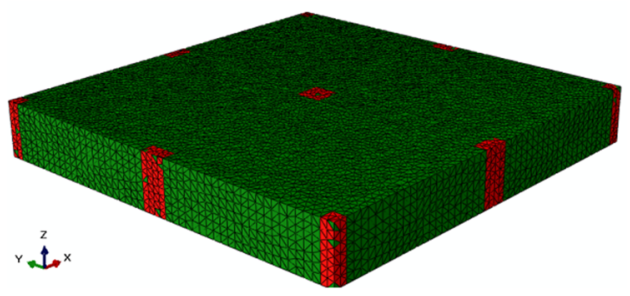

(f)

Fig. 21. FEA model with junction area void defects: (a) Junction area; (b) FEA model of junction area void defects, (c) FEA model with $1 \%$ volume defects, (d) FEA model with $2 \%$ volume defects, (e) FEA model with $4 \%$ volume defects, (f) FEA model with $5 \%$ volume defects.

Table 5

FEM model of various defect volume fractions.

\begin{tabular}{llllllll}
\hline $\begin{array}{l}\text { Name of } \\
\text { models }\end{array}$ & FE_M & FE_D & FE_C & FE_CD 1 & FE_CD 2 & FE_CD 3 & FE_CD 4 \\
\hline $\begin{array}{c}\text { Defect volume } \\
\text { fractions }\end{array}$ & $0 \%$ & $0.54 \%$ & $0.54 \%$ & $1 \%$ & $2 \%$ & $4 \%$ & $5 \%$ \\
\hline
\end{tabular}

follows:

(1) The volume fraction of material defects is imported into the script.

(2) The element number of yarn $\left(N_{f}\right)$ and the element number of matrix $N_{m}$ are counted, and the defects number of elements $N_{v f}$ and $N_{v m}$ in the yarn and matrix are calculated based on the volume fraction.

(3) After the element serial number of the yarn is searched, the $N_{v f}$ elements are selected as void defect elements. The void defect element is set as a yarn defect set, and a new yarn set is created by

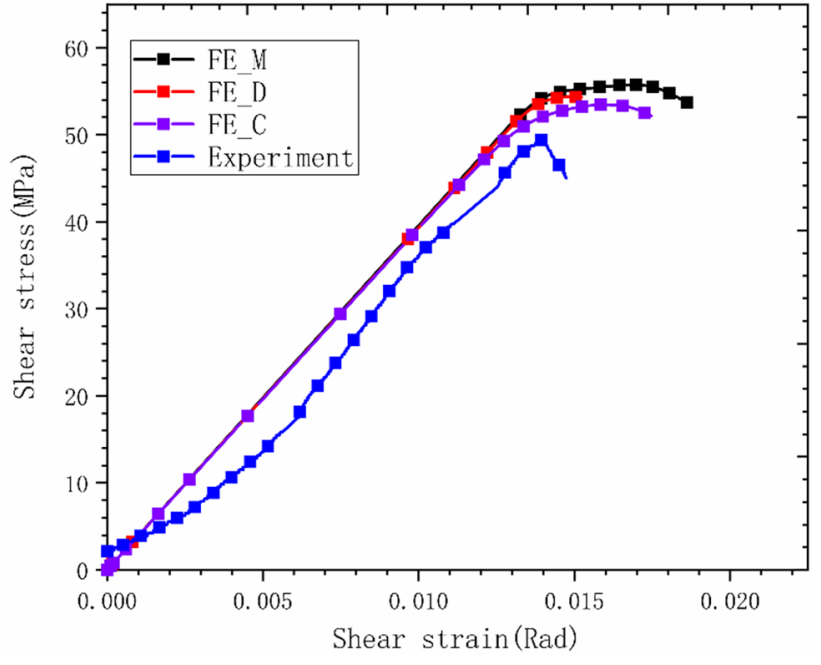

Fig. 22. The shear stress-shear strain curve. 

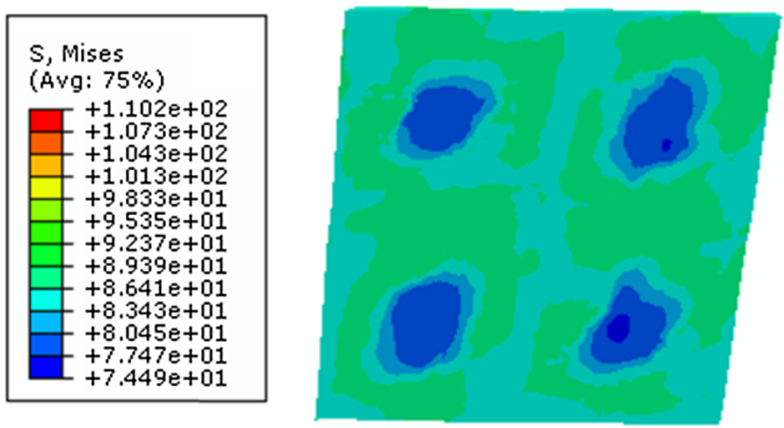

(a)
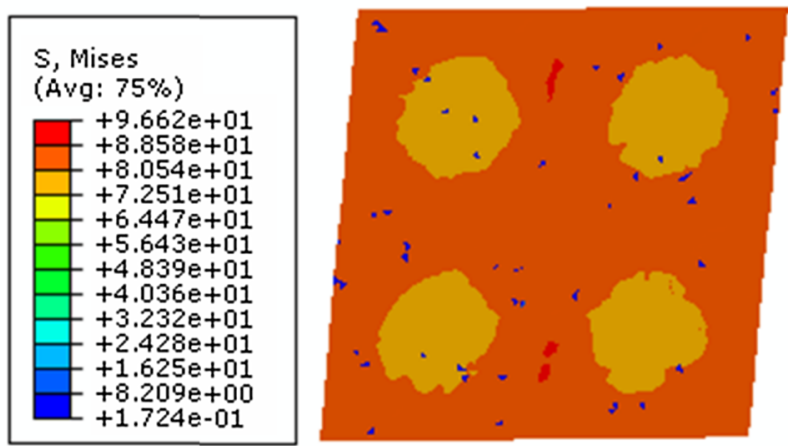

(c)
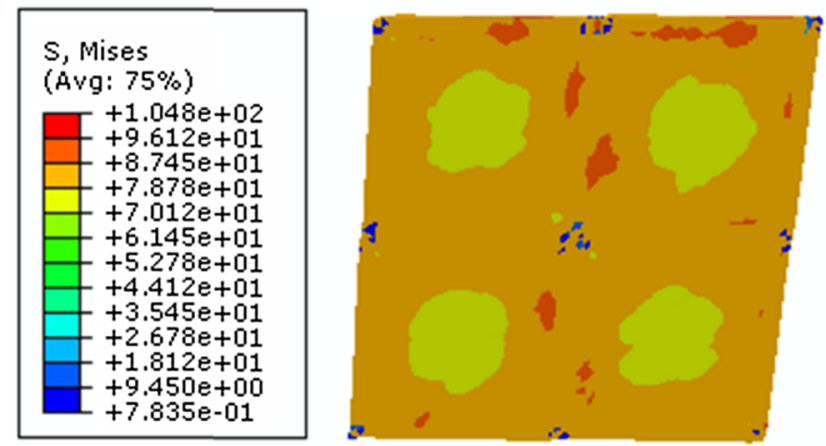

(e)
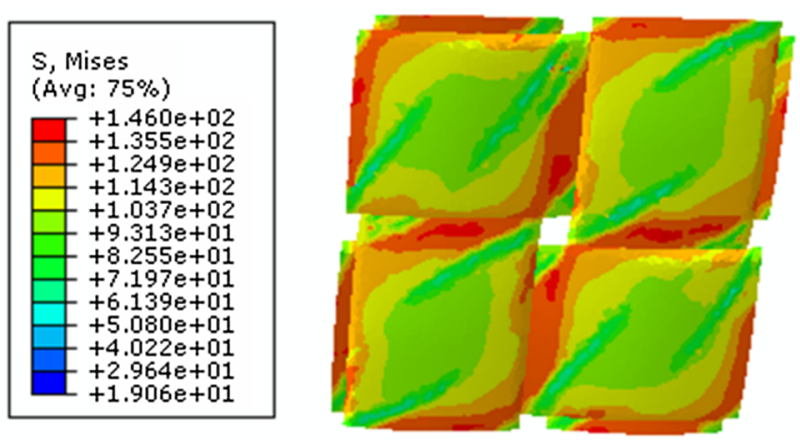

(b)
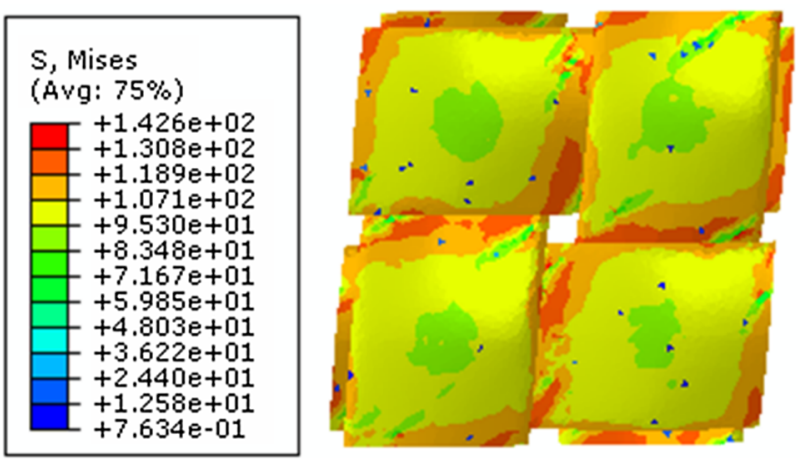

(d)
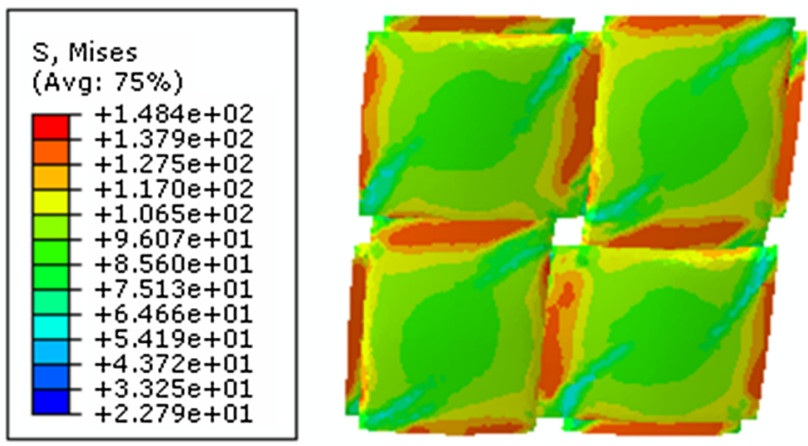

(f)

Fig. 23. Von Mises stresses contour of yarn and matrix: (a) Stresses contour of FE_M; (b) Stresses contour of FE_D; (c) Stresses contour of FE_C.

Table 6

Comparison of modulus and strength between experiment and simulation results.

\begin{tabular}{lllll}
\hline & $\begin{array}{l}\text { Shear modulus } \\
(\mathrm{MPa})\end{array}$ & $\begin{array}{l}\text { Error of shear } \\
\text { modulus }\end{array}$ & $\begin{array}{l}\text { Shear strength } \\
(\mathrm{MPa})\end{array}$ & $\begin{array}{l}\text { Error of shear } \\
\text { strength }\end{array}$ \\
\hline Experiment & 3607.8 & $/$ & 49.39 & $/$ \\
FE_M & 3957.26 & $9.69 \%$ & 55.72 & $12.82 \%$ \\
FE_D & 3934.16 & $9.05 \%$ & 54.36 & $10.06 \%$ \\
FE_C & 3921.7 & $8.7 \%$ & 53.46 & $8.22 \%$ \\
\hline
\end{tabular}

deleting the selected defective element for the initial yarn set.

(4) After the element serial number of the yarn is searched, the $N_{v m}$ elements are selected as void defect elements. The void defect element is set as a matrix defect set, and a new yarn set is created by deleting the selected defective element for the initial matrix set.

The void defects FEA model is shown in Fig. 20, where Fig. 20(a) is the matrix model and Fig. 20(b) is the yarn model. The matrix and yarn both have void defects elements with $0.54 \%$ volume, which represented by a red highlighted portion.

The spatial location of defect has been counted at the Section 3.2, it is found that most of the defects are located on the matrix at the Junction of warp weft yarn with only a few defects in the yarn. The coordinates are limited to divide a junction area as Fig. 21(a), and elements in this area are selected as void defects. In order to analysis the influence of void defects on the mechanical properties of the materials, FEA model with various defect contents is established as shown from Fig. 21(c)-(f). All the FEA model parameters are shown in Table 5. Numerical simulations are performed by using ABAQUS, and $2.5 \%$ shear displacement in the $\times$ direction is applied to simulate a shear experiment.

\section{Results analysis and discussion}

\subsection{Numerical simulation results}

Shear load simulation are performed on the three models FE_M, 

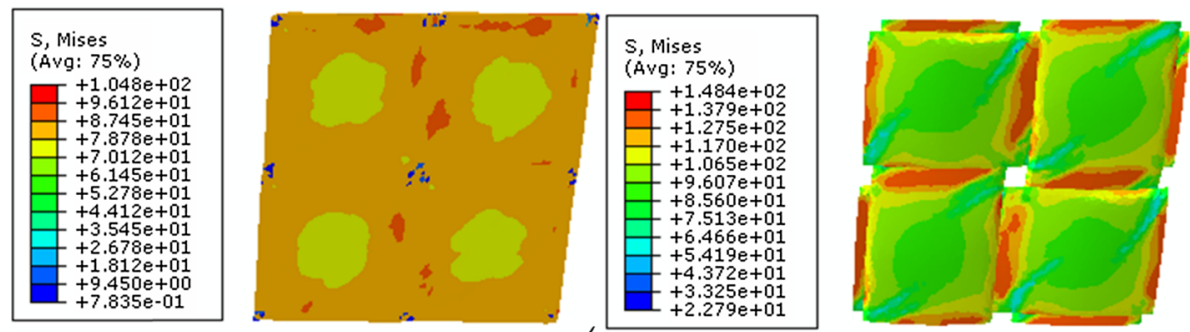

(a
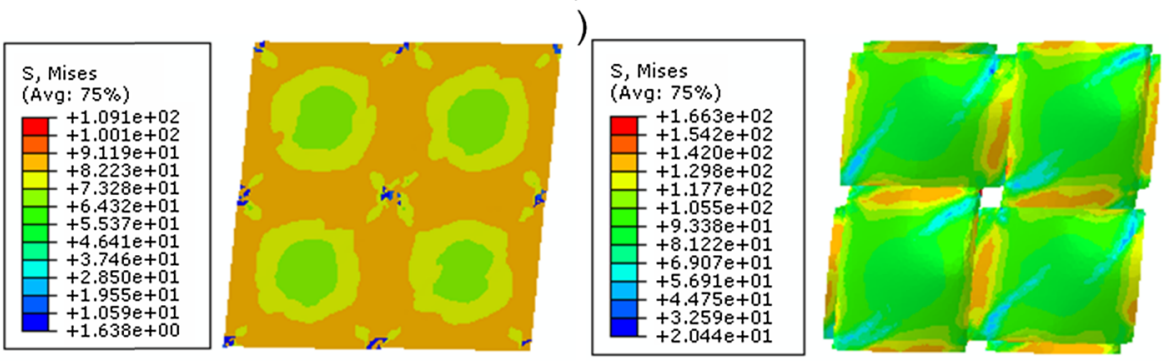

(b)
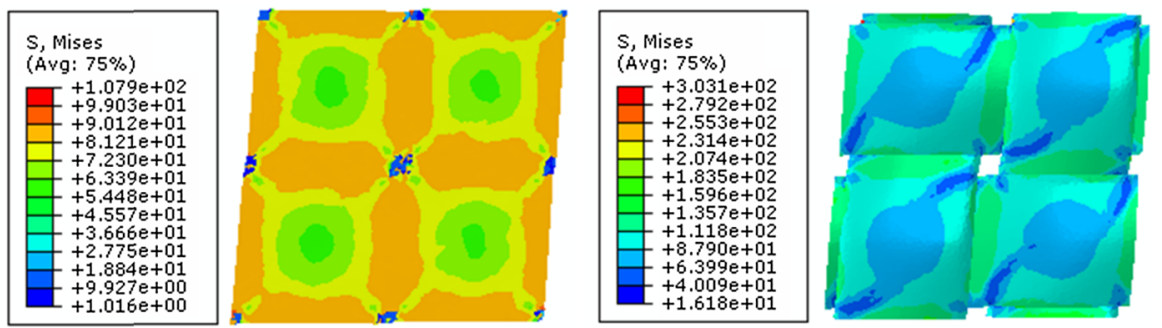

(c)
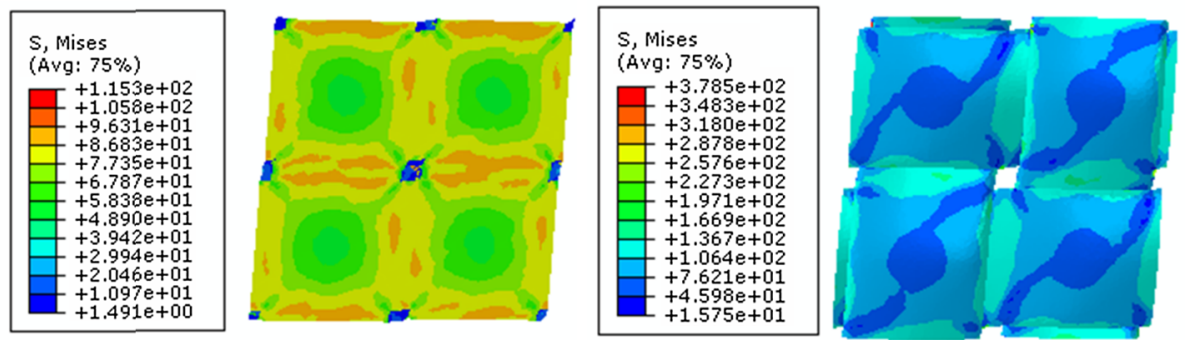

(d)
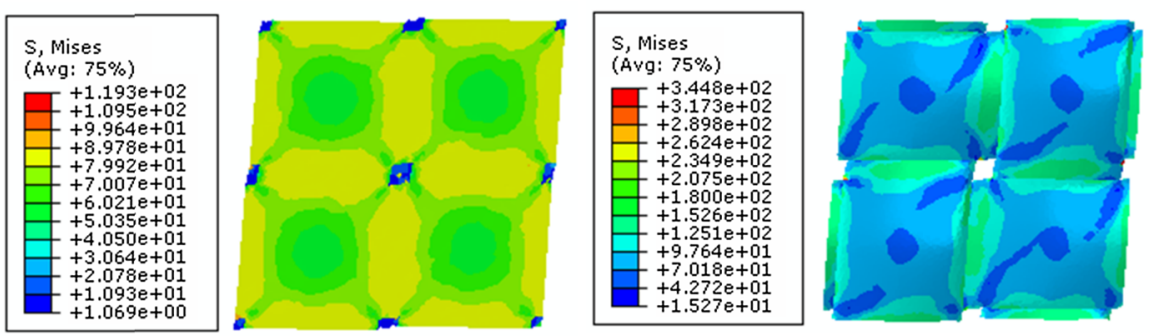

(e)

Fig. 24. Mises stress contour of the yarn and the matrix with different defect content: (a) FE_C; (b) FE_CD 1; (c) FE_CD 2; (d) FE_CD 3; (e) FE_CD 4.

FE_D and FE_C to verify the correctness of the defects position. The FEA model is deformed under the action of shear load, and the von Mises stresses contour is shown in Fig. 23. The shear stress-strain curve in the simulation and experiment is shown in Fig. 22. For more intuitive comparison, the shear modulus, shear failure strain and shear strength of each FEA model are listed in Table 6. The experimental data is set to the standard of comparison, and the shear modulus error of FE_M, FE_D and FE_C models is $9.69 \%, 9.05 \%, 8.7 \%$. The shear strength error is 


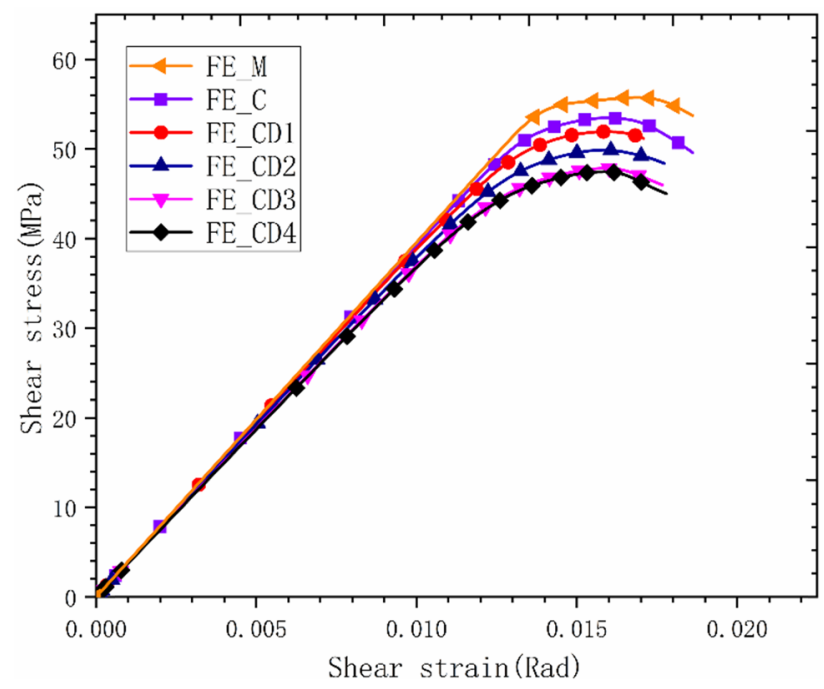

Fig. 25. Shear stress-shear strain curve of FEA model.

Table 7

Modulus and strength comparison of each FEM model.

\begin{tabular}{lllll}
\hline & $\begin{array}{l}\text { Shear modulus } \\
(\mathrm{MPa})\end{array}$ & $\begin{array}{l}\text { Error of shear } \\
\text { modulus }\end{array}$ & $\begin{array}{l}\text { Shear strength } \\
(\mathrm{MPa})\end{array}$ & $\begin{array}{l}\text { Error of shear } \\
\text { strength }\end{array}$ \\
\hline FE_M & 3957.26 & $/$ & 55.72 & $/$ \\
FE_C & 3921.7 & $0.89 \%$ & 53.46 & $4.06 \%$ \\
FE_CD 1 & 3870.6 & $2.19 \%$ & 51.92 & $6.82 \%$ \\
FE_CD 2 & 3817.5 & $3.53 \%$ & 49.88 & $10.48 \%$ \\
FE_CD 3 & 3732.9 & $5.67 \%$ & 47.84 & $14.14 \%$ \\
FE_CD 4 & 3727.8 & $5.8 \%$ & 47.45 & $14.84 \%$ \\
\hline
\end{tabular}

$12.82 \%, 10.06 \%$ and $8.22 \%$. The FE_C model simulation results are closer to the experimental results than the two other models, which further proves the rationality of defects distribution of this model. It is also stated that the void defects exist in the matrix of warp and weft yarn junction have a greater influence on the shear modulus and shear strength than a small portion of defects exist in the yarn. The defects in the matrix do not affect the distribution trend of the yarn stress from the comparison of the yarn stress contour of $\mathrm{FE}_{-} \mathrm{M}$ and $\mathrm{FE}_{-} \mathrm{C}$ model. The existence of defects in the matrix causes the yarn stress to concentrate at the junction, and the maximum yarn stress of the FE_C model is 1.64\% higher than the FE_M model, as shown in Fig. 24.

\subsection{Effect of defects on mechanical properties}

In order to analyze the influence of defects on the mechanical properties of the material, the FEA model with different volume fraction of defects is established for numerical calculation.

The shear stress-shear strain curve is shown in Fig. 25. The general FEA model is set to the standard of comparison, and the error of shear modulus and shear strength of each defect FEA model is shown in Table 7. The shear modulus and shear strength of the material are decrease with the increase of volume fraction of defects, which indicates that the void defects have a certain influence on the shear resistance ability of material. When the material defect volume fraction reaches $5 \%$, it is too many defects for the material. The void defects have little effect on the shear modulus of the materials, and the error of modulus is only $5.8 \%$. The shear strength of the material is sensitive to void defects, and the error of strength reached $14.84 \%$.

The von Mises stresses contour of the yarn and the matrix is shown in Fig. 25. The maximum stress of the matrix and the yarn increases with the increase of defect volume fraction. The existence of defects causes stress concentration and it is more obviously as the defect
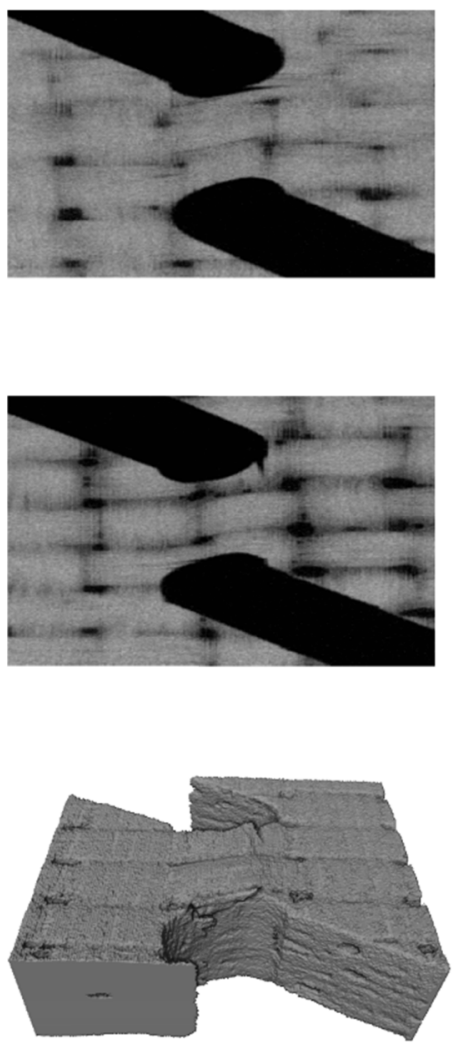
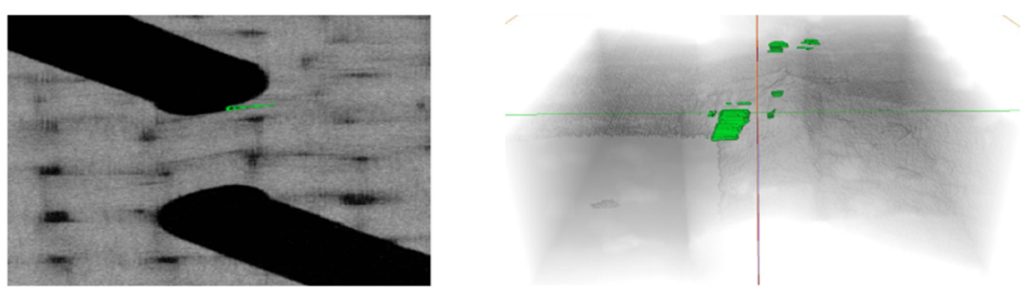

(a)

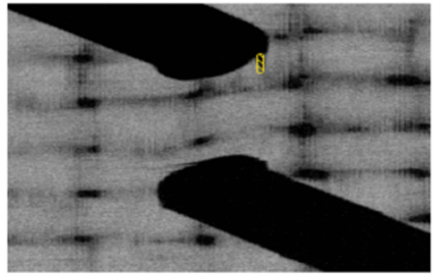

(b)

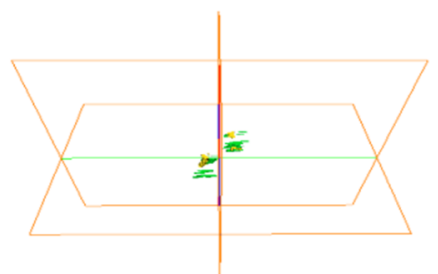

(c)

Fig. 26. The Initial damage mark: (a) Crack mark of warp yarn; (b) Crack mark of weft yarn; (c) Distribution of initial damage crack. 

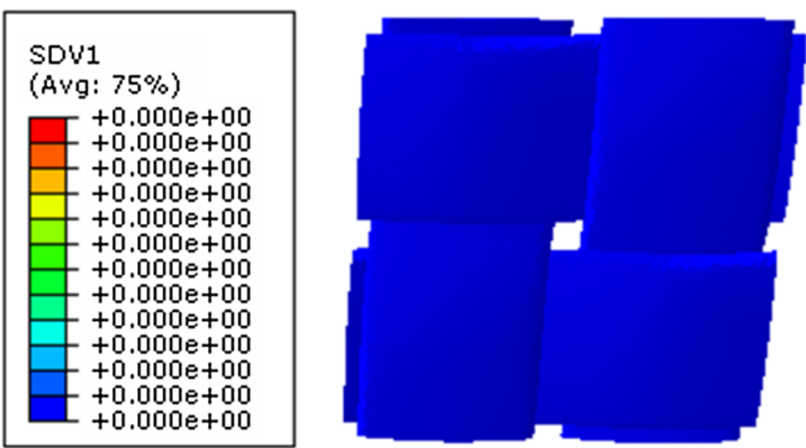

(a)
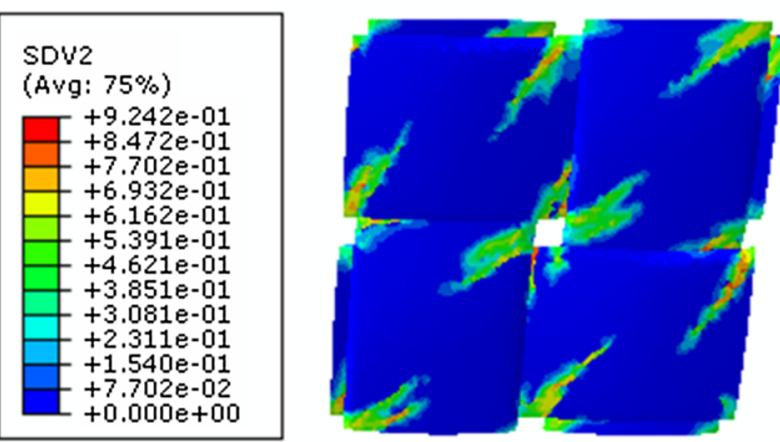

(b)

Fig. 27. Damage contour of the yarn of FE_C model: (a) SDV1 damage; (b) SDV2 damage.

\begin{tabular}{llll}
$\varepsilon_{x y}=0.0149$ & $\varepsilon_{x y}=0.0179$ & $\varepsilon_{x y}=0.0208$ \\
\hline
\end{tabular}

- Warp transverse crack
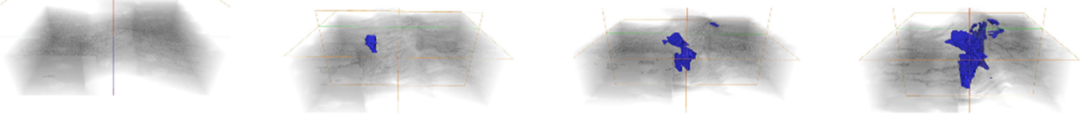

Weft longitudinal crack
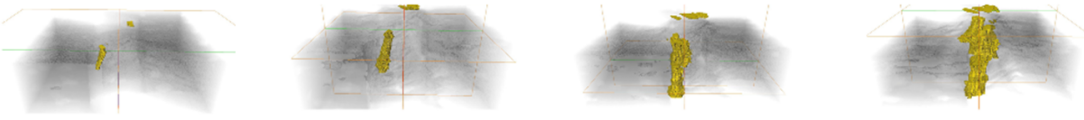

Weft transverse crack
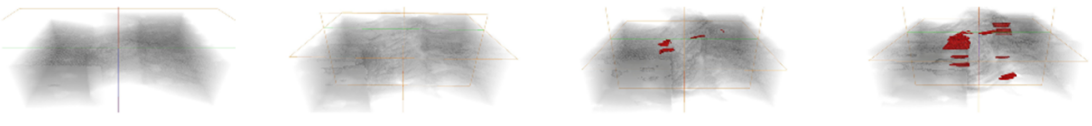

Fig. 28. Crack marks at various stages of damage.

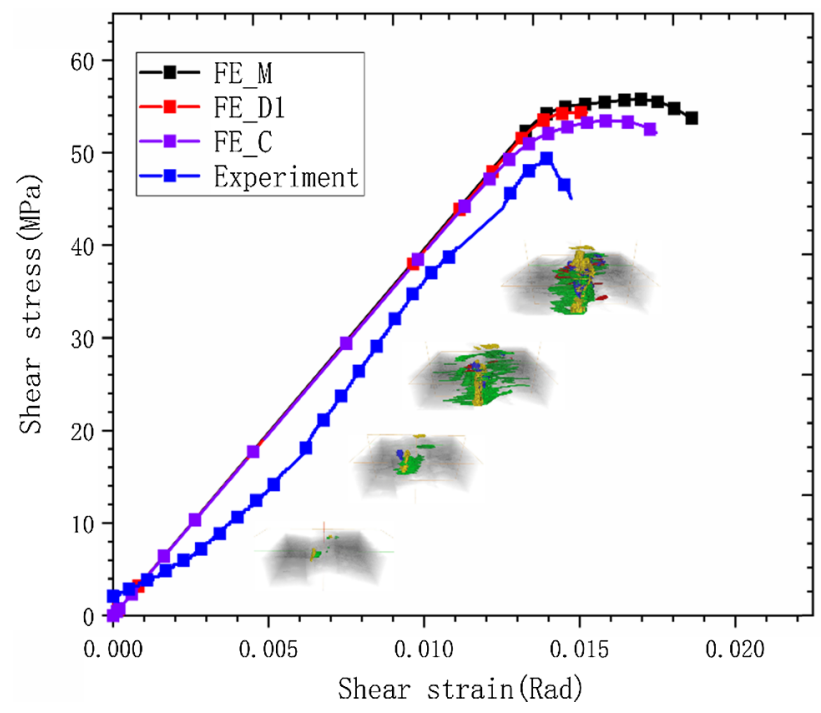

Fig. 29. The overall failure process.

volume fraction increases. Therefore, the presence of defects causes stress concentration, which is more pronounced as the porosity increases.

\subsection{Damage evolution results}

The cracks of $\mu$-CT images at various stages under shear load are classified and the different types of cracks are marked with different colors.

\subsubsection{Comparison of initial damage}

The type of initial cracks is especially important for analyzing material failure. The yarn begins to generate crack when $\varepsilon_{x y}$ is up to 0.0148 as shown in Fig. 26. A longitudinal crack is generated in the warp yarn, and is also generated in the weft yarn. The longitudinal crack of the warp yarn is marked with green as Fig. 26(a), and the longitudinal crack of the weft yarn is marked with yellow as Fig. 26(b). The shear area and cracks are reconstructed to show the spatial position of cracks in the geometric model, and the distribution of initial cracks is shown in Fig. 26(c). It is obviously that the initial crack contains only warp longitudinal cracks and weft longitudinal cracks.

In order to further verify the marking result, a damage contour of the yarn of FE_C model is retrieved for comparison as Fig. 27. Where SDV1 represent the damage of the yarn direction $(x)$, which is represented by the transverse cracks of yarn. SDV2 represent the damage of the yarn cross-sectional direction (y), which is represented by the longitudinal cracks of the yarn. The damage of the yarn is only SDV2 damage, and the SDV2 damage is not only generates in the warp yarn but also in the weft yarn. The cracks only contain the longitudinal crack of warp yarn and the longitudinal crack of weft yarn according to the 


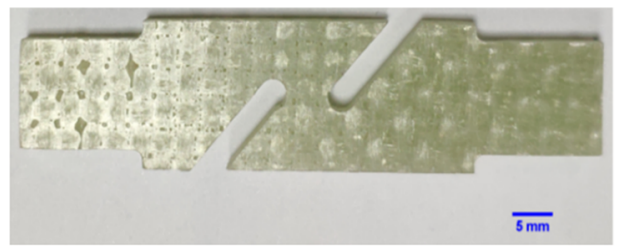

(a)

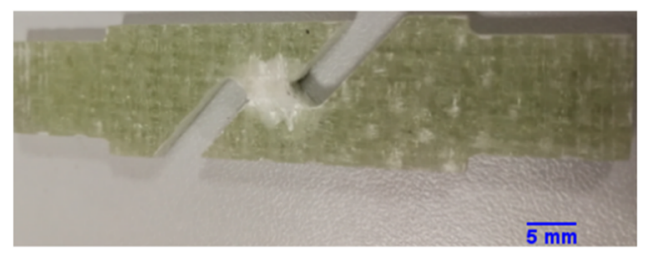

(b)

Fig. 30. Comparison of sample: (a) Before load; (b) After load.

simulation results, which is consistent with the phenomenon of the experimental results. It can be further proved that the crack generated at the initial stage of the material damage is the longitudinal crack of warp and the longitudinal crack of weft.

\subsubsection{Damage evolution process}

The damage marks at each stage are shown in Fig. 28, and the shear strains are four stages: $0.0149,0.0179,0.0208$ and 0.0227 . At the initial damage, the warp longitudinal cracks and weft longitudinal cracks is generated in the material. When the strain increases to 0.0179 , a warp transverse cracks are generated. When the strain increases to 0.0208 , the transverse cracks are generated in the weft yarns. When the strain increases to 0.0227 , all the cracks gradually extend under the load and eventually lead to the material failure. The longitudinal crack of warp yarn and the longitudinal crack of weft yarn account for the most, which is the main failure mode. The overall failure process is shown in Fig. 29, and the failed sample is shown in Fig. 30. According to the analysis results of damage evolution marks and damage simulation, it is speculated that the void defects induce the generation of warp transverse cracks. As the strain increases, all of the cracks begin to generate inside the material.

\section{Conclusion}

In this study, the effects of void defects on the mechanical properties of plain weave glass-fiber reinforced composites are analyzed through finite element method and in-situ shear test. The material defect volume and the yarn geometry are obtained from the $\mu$-CT images. A unit cell model is established by using the TEXGEN and the finite element model with void defects is generated by Monte Carlo function. Two types of FEA model is establish to analyze the influence of void defects distribution, and the rationality of the central defect model is verified. The numerical simulation and experimental results are compared to analyze the influence of void defects on the shear properties of the material. The cracks of materials in all stages of in-situ experiments is marked by using the image processing methods, and the distribution of initial cracks is compared with the damage contour of FEA model to verify the form of initial damage. The conclusion of relationship of void defects the generation and warp transverse cracks is analyzed. The finite element model and image processing tools used in this study provide a method for analyzing the influence of void defects on the mechanical properties of materials and predicting the failure modes of materials.

\section{Declaration of Competing Interest}

The authors declare that they have no known competing financial interests or personal relationships that could have appeared to influence the work reported in this paper.

\section{Acknowledgements}

This work was supported by National Natural Science Foundation of China (11802018, 11702023, 11632010, 11972081) and Beijing Natural Science Foundation (1184017).

\section{Appendix A:. Progressive damage model}

Damage variables and constitutive functions

The stiffness of the material is degraded during the damage process, and the rate of degradation is determined by the fracture energy of the yarn and the matrix. The damaged fiber yarns constitutive equation is defined as follows:

$\varepsilon_{f}=C_{f}^{d}: \sigma_{f}$

where $\varepsilon_{f}$ and $\sigma_{f}$ are the strain and stress tensor of fiber yarns, and the $C d f$ is the damaged stiffness matrix.

The damaged constitutive equation of the matrix is defined as Eq. (4):

$\varepsilon_{m}=C_{m}^{d}: \sigma_{m}$

where $\varepsilon_{m}$ and $\sigma_{m}$ are the strain and stress tensor of matrix, and the $C d m$ is the damaged stiffness matrix of matrix.

\section{Failure criterion for fiber yarns}

The initial failure state value of the fiber is calculated by Eq. (5):

$f_{f, x}=\sqrt{\frac{\varepsilon_{11}^{f, t}}{\varepsilon_{11}^{f, c}}\left(\varepsilon_{11}\right)^{2}+\left(\varepsilon_{11}^{f, c}-\frac{\left(\varepsilon_{11}^{f, t}\right)^{2}}{\varepsilon_{11}^{f, c}}\right) \varepsilon_{11}}$

where $\varepsilon_{11}, \varepsilon_{11}^{f, t}$ and $\varepsilon_{11}^{f, c}$ are the strains, tensile failure strains and compressive failure strain of fiber, respectively. When $f_{f, x}>\varepsilon_{11}^{f, t}$ the fiber will fail.

The damage variable of the fiber can be calculated from Eq. (6):

$d_{f, x}=1-\frac{\varepsilon_{11}^{f, t}}{f_{f x}} e^{-C_{11} \varepsilon_{11}^{f, t}\left(f_{f, x}-\varepsilon_{11}^{f, t}\right) L_{c} / G_{f}}$ 
where the $f_{f, x}$ is the initial failure state value of fiber, and the fracture energy of the fiber is defined as $G_{f}$. $C_{L}$ is the characteristic length of element, and $C_{11}$ is the yarns modulus in the fiber direction.

For the initial failure perpendicular to the yarn, the following failure criterion is used:

$f_{f, y}=\sqrt{\frac{\varepsilon_{22}^{f, t}}{\varepsilon_{22}^{f, c}}\left(\varepsilon_{22}\right)^{2}+\left(\varepsilon_{22}^{f, t}-\frac{\left(\varepsilon_{22}^{f, t}\right)^{2}}{\varepsilon_{22}^{f, c}}\right) \varepsilon_{22}+\left(\frac{\varepsilon_{22}^{f, t}}{\varepsilon_{12}^{f, s}}\right)^{2}\left(\varepsilon_{12}\right)^{2}}$

$f_{f, z}=\sqrt{\frac{\varepsilon_{33}^{f, t}}{\varepsilon_{33}^{f, c}}\left(\varepsilon_{33}\right)^{2}+\left(\varepsilon_{33}^{f, t}-\frac{\left(\varepsilon_{33}^{f, t}\right)^{2}}{\varepsilon_{33}^{f, c}}\right) \varepsilon_{33}+\left(\frac{\varepsilon_{33}^{f, t}}{\varepsilon_{13}^{f, s}}\right)^{2}\left(\varepsilon_{13}\right)^{2}}$

where $\varepsilon_{22}^{f, t}, \varepsilon_{33}^{f, t}$ are the tensile failure strains that are perpendicular to the fiber direction, and $\varepsilon_{22}^{f, c}, \varepsilon_{33}^{f, c}$ are the compression failure strains that are perpendicular to the fiber direction. The shear failure strains are $\varepsilon_{12}^{f, s}$ and $\varepsilon_{13}^{f, s}$. The threshold values of $f_{f, y}$ and $f_{f, z}$ are $\varepsilon_{22}^{f, t}$ and $\varepsilon_{33}^{f, t}$, respectively.

The damage variables of the matrix can be calculated from Eq. (9) and Eq. (10):

$d_{m, \mathrm{y}}=1-\frac{\varepsilon_{22}^{f, t}}{f_{m y}} e^{-C_{22} \varepsilon_{22}^{f, t}\left(f_{m, y}-\varepsilon_{22}^{f, t}\right) L_{c} / G_{m}}$

$d_{m, z}=1-\frac{\varepsilon_{33}^{f, t}}{f_{m z}} e^{-C_{33} \varepsilon_{33}^{f, t}\left(f_{m, z}-\varepsilon_{33}^{f, t}\right) L_{c} / G_{m}}$

where $C_{22}, C_{33}$ are the yarns moduli perpendicular to the fiber direction, and the fracture energy of the matrix is defined as $G_{f}$. As damage progressing, the overall stiffness coefficient is reduced.

When the yarn and the matrix are damaged, the stiffness matrix can be updated by Eq. (11):

$C_{f}^{d}=\left[\begin{array}{cccccc}\alpha C_{11} & \alpha \beta C_{12} & \alpha \gamma C_{13} & 0 & 0 & 0 \\ & \beta C_{22} & \beta \gamma C_{23} & 0 & 0 & 0 \\ & & \gamma C_{33} & 0 & 0 & 0 \\ & & & \alpha \beta C_{44} & 0 & 0 \\ \text { sym } & & & & \alpha \gamma C_{55} & 0 \\ & & & & & \beta \gamma C_{66}\end{array}\right]$

where $\alpha=\left(1-d_{f, x}\right), \beta=\left(1-d_{m, y}\right), \gamma=\left(1-d_{m, z}\right)$ and $C_{i j}$ are the components of the stiffness matrix in the initial state.

\section{Failure criterion for matrix}

The initial failure state value of the matrix is calculated by Eq. (12):

$f_{m, x(y / z)}=\sqrt{\frac{\varepsilon^{m, t}}{\varepsilon^{m, c}}\left(\varepsilon_{11(22 / 33)}\right)^{2}+\left(\varepsilon^{m, t}-\frac{\left(\varepsilon^{m, t}\right)^{2}}{\varepsilon^{m, c}}\right) \varepsilon_{11(22 / 33)}+\left(\frac{\varepsilon^{m, t}}{\varepsilon^{m, s}}\right)^{2}\left(\varepsilon_{12(23 / 13)}\right)^{2}+\left(\frac{\varepsilon^{m, t}}{\varepsilon^{m, s}}\right)^{2}\left(\varepsilon_{13(12 / 23)}\right)^{2}}$

where $\varepsilon^{m, t}$ is the tensile failure strain of the matrix, and $\varepsilon^{m, c}$ is the compression failure strain. The shear failure strain of the matrix is $\varepsilon^{m, s}$. When the $f_{m, x(y / z)}>\varepsilon^{m, t}$, the matrix begins to generate damage.

For matrix failure, the following failure criterion is used:

$d_{m, x(y / z)}=1-\frac{\varepsilon^{f, t}}{f_{m, x(y / z)}} e^{-C_{11 \varepsilon^{f, t}}\left(f_{m, x(y / z)}-\varepsilon^{f, t}\right) L_{c} / G_{m}}$

The stiffness matrix of matrix can be updated by Eq. (14):

$C_{m}^{d}=\left[\begin{array}{cccccc}\alpha^{\prime} C_{11} & \alpha^{\prime} \beta^{\prime} C_{12} & \alpha^{\prime} \gamma^{\prime} C_{13} & 0 & 0 & 0 \\ & \beta^{\prime} C_{22}^{\prime} & \beta^{\prime} \gamma^{\prime} C_{23} & 0 & 0 & 0 \\ & & \gamma^{\prime} C_{33} & 0 & 0 & 0 \\ & & & \alpha^{\prime} \beta^{\prime} C_{44} & 0 & 0 \\ & & & & \alpha^{\prime} \gamma^{\prime} C_{55} & 0 \\ \text { sym } & & & & & \beta \gamma C_{66}\end{array}\right]$

where $\alpha^{\prime}=\left(1-d_{m, x}\right), \beta^{\prime}=\left(1-d_{m, z}\right), \gamma^{\prime}=\left(1-d_{m, y}\right)$.

The stresses in the user subroutine UMAT are updated according to the Eq. (15):

$\sigma_{n+1}=\sigma_{n}+C^{d}: \Delta \varepsilon_{n+1}$

where $\sigma_{n}$ and $\sigma_{n+1}$ are the stresses at step $\mathrm{n}$ and $n+1$, and $\Delta \varepsilon_{n+1}$ is the strain increment of step $n+1$.

The reduction of element stiffness matrix sometimes causes the calculation results to not converge, and the viscosity regularization can keep the tangent stiffness matrix of the damaged unit still positive in a small incremental step. The viscous damage variable of the incremental step can be calculated from Eq. (16):

$d_{j}^{v}=\frac{\eta}{\eta+\Delta t} d_{j, o l d}^{v}+\frac{\Delta t}{\eta+\Delta t} d_{j}(j=f, m)$

where $\Delta t$ is the time increment, and $d v$ j,old is the viscous damage variable of the previous incremental step. The viscosity coefficient is represented 
by $\eta$. In general, the value of the viscosity coefficient is much smaller than the time increment.

Therefore, the Jacobian matrix of yarns and matrix can be formulated by Eq. (17) and Eq. (18):

$$
\begin{aligned}
& \frac{\partial \sigma}{\partial \varepsilon}(f)=C_{f}^{d}+\left(\frac{\partial C_{f}^{d}}{\partial d_{f, x}}: \varepsilon\right)\left(\frac{\partial d_{f, x}}{\partial f_{f, x}} \cdot \frac{\partial f_{f, x}}{\partial \varepsilon}\right)+\left(\frac{\partial C_{f}^{d}}{\partial d_{m, y}}: \varepsilon\right)\left(\frac{\partial d_{m, y}}{\partial f_{m, y}} \cdot \frac{\partial f_{m, y}}{\partial \varepsilon}\right)+\left(\frac{\partial C_{f}^{d}}{\partial d_{m, z}}: \varepsilon\right)\left(\frac{\partial d_{m, z}}{\partial f_{m, z}} \cdot \frac{\partial f_{m, z}}{\partial \varepsilon}\right) \\
& \frac{\partial \sigma}{\partial \varepsilon}(m)=C_{m}^{d}+\left(\frac{\partial C_{m}^{d}}{\partial d_{m, x}}: \varepsilon\right)\left(\frac{\partial d_{m, x}}{\partial f_{m, x}} \cdot \frac{\partial f_{m, x}}{\partial \varepsilon}\right)+\left(\frac{\partial C_{m}^{d}}{\partial d_{m, y}}: \varepsilon\right)\left(\frac{\partial d_{m, y}}{\partial f_{m, y}} \cdot \frac{\partial f_{m, y}}{\partial \varepsilon}\right)+\left(\frac{\partial C_{m}^{d}}{\partial d_{m, z}}: \varepsilon\right)\left(\frac{\partial d_{m, z}}{\partial f_{m, z}} \cdot \frac{\partial f_{m, z}}{\partial \varepsilon}\right)
\end{aligned}
$$

where $\mathrm{Cd} \mathrm{f}, \mathrm{Cd} \mathrm{m}$ are the updated stiffness coefficient after the yarn, matrix get damage.

\section{Appendix B:. Periodic boundary conditions}

The meso-structure of braided composites has good periodicity. Ordinary boundary conditions cannot reflect the interaction of unit cells, and the displacement and stress-strain between unit cells cannot be continuous. Considering the application of periodic boundary conditions to achieve constraints, the displacement, stress and strain are consistent between the individual cells. The schematic diagram of unit cell is shown in Fig. B1, and the distribution of stress and strain in the model can also be used for translational symmetric transformation. The macroscopic strain and relative displacement of corresponding points in different unit cells have the relationship of Eq. (19), because of the same transformation mode of displacement and strain.

$$
\left\{\begin{array}{c}
u^{\prime}-u=\left(x^{\prime}-x\right) \varepsilon_{x}^{0}+\left(y^{\prime}-y\right) \gamma_{x y}^{0}+\left(z^{\prime}-z\right) \gamma_{x z}^{0} \\
v^{\prime}-v=\left(y^{\prime}-y\right) \varepsilon_{y}^{0}+\left(z^{\prime}-z\right) \gamma_{y z}^{0} \\
w^{\prime}-w=\varepsilon_{z}^{0}
\end{array}\right.
$$

where $x y, z$ are the coordinates of point A, and $u, v, w$ are the displacements of point A. The $x^{\prime}, y^{\prime}, z^{\prime}$ and $u^{\prime}, v^{\prime}, w^{\prime}$ are the coordinates and displacement of point $\mathrm{A} 1$, and the $\mathrm{A} 1$ is corresponding to point A. $\varepsilon_{x}^{0}, \varepsilon_{y}^{0}, \varepsilon_{z}^{0}$ are the macroscopic strains of the model.

The periodic boundary conditions are applied to constrain the displacement, stress and strain to be consistent between the unit cells. A script is written to implement plane, edge and vertex constraints on unit cell.

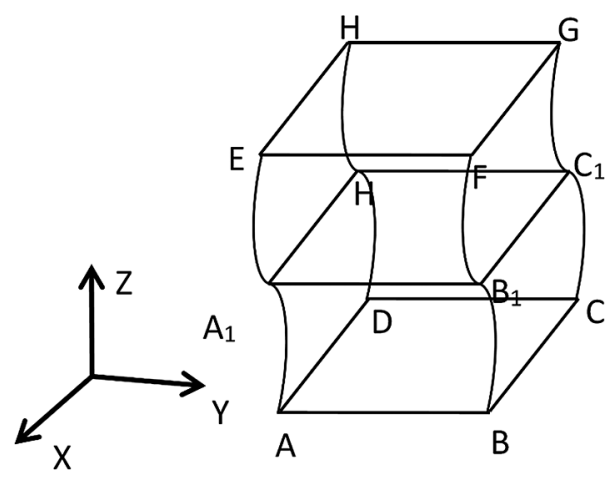

Fig. B1. Schematic diagram of unit cell.

\section{Appendix C. Supplementary data}

Supplementary data to this article can be found online at https://doi.org/10.1016/j.compstruct.2019.111746.

\section{References}

[1] Kang H, Shan Z, Zang Y, Liu F. Progressive damage analysis and strength properties of fiber-bar composites reinforced by three-dimensional weaving under uniaxial tension. Compos Struct 2016;141:264-81.

[2] Yang J-S, Xiong J, Ma L, Feng L-N, Wang S-Y, Wu L-Z. Modal response of allcomposite corrugated sandwich cylindrical shells. Compos Sci Technol 2015;115:9-20.

[3] De Jong S, Postle R. A general energy analysis of fabric mechanics using optimal control theory. Text Res J 1978;48:127-35.

[4] Sinoimeri A, Dréan J. Mechanical behavior of the plain weave structure using energy methods: fabric uniaxial extension. Text Res J 1997;67:370-8.

[5] Ge J, He C, Liang J, Chen Y, Fang D. A coupled elastic-plastic damage model for the mechanical behavior of three-dimensional (3D) braided composites. Compos Sci Technol 2018;157:86-98.

[6] Miravete A, Bielsa J, Chiminelli A, Cuartero J, Serrano S, Tolosana N, et al. 3D mesomechanical analysis of three-axial braided composite materials. Compos Sci Technol 2006;66:2954-64.

[7] Lu Z, Xia B, Yang Z. Investigation on the tensile properties of three-dimensional full five-directional braided composites. Comput Mater Sci 2013;77:445-55.

[8] Drach A, Drach B, Tsukrov I. Processing of fiber architecture data for finite element modeling of 3D woven composites. Adv Eng Softw 2014;72:18-27.

[9] Verpoest I, Lomov SV. Virtual textile composites software WiseTex: integration with micro-mechanical, permeability and structural analysis. Compos Sci Technol 2005; 65:2563-74.

[10] Lin H, Brown LP, Long AC. Modelling and simulating textile structures using TexGen. Advanced Materials Research: Trans Tech Publ; 2011, pp. 44-47.

[11] Sharma R, Mahajan P, Mittal RK. Elastic modulus of 3D carbon/carbon composite using image-based finite element simulations and experiments. Compos Struct 2013;98:69-78.

[12] Blacklock M, Bale H, Begley M, Cox B. Generating virtual textile composite specimens using statistical data from micro-computed tomography: 1D tow representations for the binary model. J Mech Phys Solids 2012;60:451-70.

[13] Rinaldi RG, Blacklock M, Bale H, Begley MR, Cox BN. Generating virtual textile composite specimens using statistical data from micro-computed tomography: 3D tow representations. J Mech Phys Solids 2012;60:1561-81.

[14] Bale H, Blacklock M, Begley MR, Marshall DB, Cox BN, Ritchie RO. Characterizing three-dimensional textile ceramic composites using synchrotron x-ray micro-computed-tomography. J Am Ceram Soc 2012;95:392-402. 
[15] Naouar N, Vidal-Sallé E, Schneider J, Maire E, Boisse P. Meso-scale FE analyses of textile composite reinforcement deformation based on X-ray computed tomography. Compos Struct 2014;116:165-76.

[16] Huang W, Causse P, Brailovski V, Hu H, Trochu F. Reconstruction of mesostructural material twin models of engineering textiles based on micro-CT aided geometric modeling. Compos Part A Appl Sci Manuf; 2019:105481.

[17] Djukic LP, Herszberg I, Walsh WR, Schoeppner GA, Prusty BG, Kelly DW. Contrast enhancement in visualisation of woven composite tow architecture using a MicroCT scanner. part 1: fabric coating and resin additives. Compos A Appl Sci Manuf 2009;40:553-65.

[18] Djukic LP, Herszberg I, Walsh WR, Schoeppner GA, Prusty BG. Contrast enhancement in visualisation of woven composite architecture using a MicroCT scanner. Part 2: tow and preform coatings. Compos A Appl Sci Manuf 2009;40:1870-9.

[19] Kosek M, Sejak P. Visualization of voids in actual C/C woven composite structure. Compos Sci Technol 2009;69:1465-9.

[20] Shigang A, Daining F, Rujie H, Yongmao P. Effect of manufacturing defects on mechanical properties and failure features of 3D orthogonal woven C/C composites. Compos B Eng 2015;71:113-21.

[21] Yousaf Z, Potluri P, Withers P, Mollenhauer D, Zhou E, Duning S. Digital element simulation of aligned tows during compaction validated by computed tomography (CT). Int J Solids Struct 2018;154:78-87.

[22] Dietrich S, Koch M, Elsner P, Weidenmann K. Measurement of sub-surface core damage in sandwich structures using in-situ hertzian indentation during $\mathrm{X}$-ray computed tomography. Exp Mech 2014;54:1385-93.

[23] Wright P, Moffat A, Sinclair I, Spearing S. High resolution tomographic imaging and modelling of notch tip damage in a laminated composite. Compos Sci Technol 2010;70:1444-52

[24] Williams J, Yazzie K, Padilla E, Chawla N, Xiao X, De Carlo F. Understanding fatigue crack growth in aluminum alloys by in situ X-ray synchrotron tomography. Int J Fatigue 2013;57:79-85.

[25] Dezecot S, Buffiere J-Y, Koster A, Maurel V, Szmytka F, Charkaluk E, et al. In situ 3D characterization of high temperature fatigue damage mechanisms in a cast aluminum alloy using synchrotron X-ray tomography. Scr Mater 2016;113:254-8.

[26] Martyniuk K, Sørensen BF, Modregger P, Lauridsen EM. 3D in situ observations of glass fibre/matrix interfacial debonding. Compos A Appl Sci Manuf 2013;55:63-73.

[27] Böhm R, Stiller J, Behnisch T, Zscheyge M, Protz R, Radloff S, et al. A quantitative comparison of the capabilities of in situ computed tomography and conventional computed tomography for damage analysis of composites. Compos Sci Technol 2015;110:62-8.

[28] Garcea S, Wang Y, Withers P. X-ray computed tomography of polymer composites. Compos Sci Technol 2018;156:305-19.

[29] Mazars V, Caty O, Couégnat G, Bouterf A, Roux S, Denneulin S, et al. Damage investigation and modeling of 3D woven ceramic matrix composites from X-ray tomography in-situ tensile tests. Acta Mater 2017;140:130-9.

[30] Perrier A, Touchard F, Chocinski-Arnault L, Mellier D. Quantitative analysis by micro-CT of damage during tensile test in a woven hemp/epoxy composite after water ageing. Compos A Appl Sci Manuf 2017;102:18-27.

[31] Wang $\mathrm{H}$, Wang Z-w. Statistical analysis of yarn feature parameters in C/epoxy plainweave composite using micro CT with high-resolution lens-coupled detector. Appl Compos Mater 2016;23:601-22.

[32] Vanaerschot A, Panerai F, Cassell A, Lomov SV, Vandepitte D, Mansour NN. Stochastic characterisation methodology for 3-D textiles based on micro-tomography. Compos Struct 2017;173:44-52.

[33] Vanaerschot A, Cox BN, Lomov SV, Vandepitte D. Stochastic framework for quantifying the geometrical variability of laminated textile composites using microcomputed tomography. Compos A Appl Sci Manuf 2013;44:122-31.

[34] Wang H, Wang,. Z-w. A variable metric stochastic theory of textile composites with random geometric parameters of yarn cross-section. Compos Struct 2015;126:78-88.

[35] Wang H, Wang Z-w. Quantification of effects of stochastic feature parameters of yarn on elastic properties of plain-weave composite-part 2: statistical predictions vs. mechanical experiments. Compos A Appl Sci Manuf 2016;84:147-57.

[36] Wang H, Wang Z-w. Quantification of effects of stochastic feature parameters of yarn on elastic properties of plain-weave composite. Part 1: theoretical modeling. Compos A Appl Sci Manuf 2015;78:84-94.

[37] Pun T. A new method for grey-level picture thresholding using the entropy of the histogram. Signal Process 1980;2:223-37.

[38] Shigang A, Xiaolei Z, Yiqi M, Yongmao P, Daining F. Finite element modeling of 3D orthogonal woven $\mathrm{C} / \mathrm{C}$ composite based on micro-computed tomography experiment. Appl Compos Mater 2014;21:603-14.

[39] Yu B, Blanc R, Soutis C, Withers P. Evolution of damage during the fatigue of 3D woven glass-fibre reinforced composites subjected to tension-tension loading observed by time-lapse X-ray tomography. Compos A Appl Sci Manuf 2016;82:279-90.

[40] Nouri H, Guessasma S, Roger F, Ayadi A, Maitournam H. Exploring damage kinetics in short glass fibre reinforced thermoplastics. Compos Struct 2017;180:63-74.

[41] Guo-dong F, Jun L, Bao-lai W. Progressive damage and nonlinear analysis of 3D four-directional braided composites under unidirectional tension. Compos Struct 2009;89:126-33.

[42] Marrey RV. Finite element micromechanics models for predicting stiffness and strength of textile composite materials; 1996.

[43] Version A. 6.13, Analysis User's Manual. Dassault Systemes Simulia Corp, Providence, RI. 2013.

[44] Jahanian E, Zeinedini A. Influence of drilling on mode II delamination of E-glass/ epoxy laminated composites. Theor Appl Fract Mech 2018;96:398-407.

[45] Chamis CC. Mechanics of composite materials: past, present, and future. J Compos Tech Res 1989;11:3-14.

[46] Sherburn M. Geometric and mechanical modelling of textiles. University of Nottingham; 2007.

[47] Wang P, Lei H, Zhu X, Chen H, Wang C, Fang D. Effect of manufacturing defect on mechanical performance of plain weave carbon/epoxy composite based on 3D geometrical reconstruction. Compos Struct 2018;199:38-52. 